\title{
A Comparison of the Volatile Components of Cold Pressed Hamlin and Valencia (Citrus sinensis (L.) Osbeck) Orange Oils Affected by Huanglongbing
}

\author{
Brittany M. Xu, George L. Baker, Paul J. Sarnoski, and Renée M. Goodrich-Schneider \\ Department of Food Science and Human Nutrition, University of Florida, 359 FSHN Bldg., 572 Newell Drive, Gainesville, \\ FL 32611, USA \\ Correspondence should be addressed to Renée M. Goodrich-Schneider; goodrich@ufl.edu
}

Received 14 July 2017; Revised 16 September 2017; Accepted 10 October 2017; Published 15 November 2017

Academic Editor: Flora V. Romeo

Copyright (C) 2017 Brittany M. Xu et al. This is an open access article distributed under the Creative Commons Attribution License, which permits unrestricted use, distribution, and reproduction in any medium, provided the original work is properly cited.

\begin{abstract}
Volatiles from huanglongbing (HLB) symptomatic and asymptomatic cold pressed orange oils from Florida Hamlin and Valencia fruit were assessed. Qualitative gas-liquid chromatography studies showed the presence of several compounds ( $\beta$-longifolene, perillene, and 4-decenal) which are not commonly identified in Citrus sinensis (L.) Osbeck oils. Oils derived from huanglongbing symptomatic fruit had lower concentrations of linalool, decanal, citronellol, neral, geranial, carvone, dodecanal, and 2-decenal and higher concentrations of citronellal compared to asymptomatic fruit. A comparison to historic literature of orange oil investigations before HLB was of issue in Florida orange crops showed lower levels of linalool, decanal, neral, and geranial in Hamlin peel oil samples, as well as higher levels of dodecanal. Valencia peel oil samples showed lower concentrations of linalool and increased concentration of citronellol and dodecanal. As a result of huanglongbing (HLB) phenomena, the concentrations of several important volatiles found in Hamlin and Valencia peel oil profiles have changed compared to historic values. Differences in volatile concentrations of symptomatic and asymptomatic HLB affected peel oil compounds in orange fruit are identified.
\end{abstract}

\section{Introduction}

Huanglongbing (HLB), also known as citrus greening disease, is a bacterial citrus disease. The causative bacterial species in the state of Florida is Candidatus Liberibacter asiaticus [1], which is vectored by the Asian citrus psyllid Diaphorina citri Kuwayama [2]. To date, an infected tree cannot be cured of HLB [1]. There are several noticeable anatomical and physiological changes which occur before orange fruit productivity drops, including root system decay, changes in the fruit, and asymmetrical leaf chlorosis, also known as yellow blotchy mottle [2]. Fruit which are symptomatic for HLB are somewhat green in color, small, and misshapen and contain aborted seeds [2]. HLB is an orange tree disease considered devastating to the citrus industry in Florida and other areas of the world, given the widespread infection of groves in a relatively short period of time, resulting in orange farmers to abandon or destroy their crop, year over year. Between the years of 2006 and 2011, over 6660 jobs and more than $\$ 3.63$ billion in revenue were lost in Florida due to HLB [3].

Cold pressed orange peel oil is a valuable commodity to the global beverage industry derived from a byproduct of orange juice production which may otherwise become animal feed or waste [4]. Wide variations in oil yield from Florida oranges have been found but are generally in the range of $0.11-0.58 \%$ of the total orange weight [5]. While commercial quantities of oil are present in oranges before the fruit is ready to harvest, oil content reaches a maximum when the fruit is fully mature [6]. The most common instrument for extracting cold pressed oil from oranges is the JBT (formerly FMC) inline extraction system [7]. With this equipment, the oil is extracted simultaneously with the juice from the orange peel. Orange oil is washed away from the orange peel with an excess of water to create a crude emulsion, which can be further processed into pure cold pressed oil 24-48 hours after extraction [8]. Cold pressed orange oil is used in beverages, including juices and juice concentrates. Orange 
oil is frequently added back to the concentrated product it is derived from or is added to other citrus juices [8]. Cold pressed orange oil gives juice sweet, fruity, and green top notes and is usually added to orange juice concentrate at a volume-to-volume ratio of $0.01 \%$ [8]. Cold pressed orange oil can also be used in desserts, soft drinks, chewing gum, and confections [7].

While no previous studies have investigated the effect of HLB on cold pressed orange oil, several have studied the effects of HLB on the chemical constituents of orange juice $[9,10]$. Dagulo et al. investigated the effect of HLB on orange juices made from HLB unaffected (control), asymptomatic, and symptomatic Valencia fruit [9]. Their results showed that juice produced from HLB symptomatic fruit has fewer overall esters, aldehydes, and total sesquiterpenes than juice extracted from control fruit. Juice produced from HLB symptomatic fruit in their studies contained increased levels of alcohols and terpenes. Overall, the chemical changes observed for juice produced from HLB symptomatic fruit were comparable to the chemical characteristics of juice produced from immature fruit and have a less favorable aroma profile compared to HLB unaffected fruit [9]. Moreover, they showed that orange juice produced from HLB asymptomatic fruit did not show consistent differences from control fruit [9].

Baldwin et al. studied the effects of HLB on juices produced from symptomatic and control (unaffected) Valencia, Hamlin, and Midsweet oranges [10]. This study was conducted over the 2007 and 2008 harvest seasons, with multiple harvests per season. Their results showed that, during the 2007 season, hexanol levels were higher in juice derived from symptomatic Hamlin fruit than in juice produced from control orange fruit. Ethanol concentrations were higher in juice produced from HLB symptomatic Midsweet fruit, while hexanal, cis-3-hexenol, and linalool concentrations were higher in juice produced from control Midsweet fruit. Valencia juice did not show any variation in volatiles by disease status but did show differences between harvest times. During the 2008 season, no differences were seen between orange juices from Midsweet fruit. Hamlin showed higher levels of acetaldehyde, octanal, ethanol, cis-3-hexenol, and sabinene in control juice and higher levels of $\beta$-myrcene and ethyl hexanoate in juice produced from symptomatic fruit. Juice derived from symptomatic Valencia oranges showed higher levels of ethanol and sabinene and juice from control fruit showed higher levels of hexanol and ethyl acetate [10]. Overall, these data show that there can be season to season and cultivar differences in how HLB affects volatile concentrations in orange juices.

The objective of this study was to investigate the volatile components of cold pressed oil from HLB symptomatic and asymptomatic oranges. No previous studies have been published which investigate these effects.

\section{Materials and Methods}

2.1. Harvesting and Orange Trees. Florida grown Hamlin and Valencia oranges were each harvested twice per year. Fruit were harvested from established groves at the University of Florida Citrus Research and Education Center in Lake Alfred, Florida. Fruit were harvested both early and late in the respective variety's season for both Valencia and Hamlin oranges. The purpose of these different harvests was to test the effect HLB has on multiple cultivars of oranges at multiple points in the season. Disease stage and maturity of fruit were assessed by a trained horticulturist using established protocols [14]. Oranges were harvested by hand for the 20152016 season. Hamlin oranges were harvested on November 15, 2015, and January 14, 2016. Valencia oranges were harvested on February 11, 2016, and March 31, 2016.

Approximately 30 trees per variety were harvested. The trees harvested were in adjacent rows $(n=2-5)$. Approximately 300 kilograms each of asymptomatic (AS) and symptomatic (SY) oranges were collected during each harvest. SY fruit were noted to be mature but with characteristic outward greening symptoms including small fruit with reversed ripening where the stylar end remains green. While some trees contained both AS and SY fruit, many trees contained nearly $100 \%$ SY fruit. These trees commonly displayed overall sparse foliage on the tree and yellow blotchy mottle on the leaves. AS fruit appeared outwardly healthy, were overall larger, and did not display the reversed ripening common with HLB SY fruit. Significant quantities of HLB unaffected fruit can no longer be found in the state of Florida, as HLB infection rate at the grove level is near $100 \%$ [15]. Thus, only HLB SY and AS fruit were utilized for this study.

2.2. Cold Pressed Oil Extraction. Fruit were stored in a cold room at $4^{\circ} \mathrm{C}$ after harvest until processing. Processing of the raw oranges into cold pressed orange oil was performed in the Pilot Plant at the Citrus Research and Education Center in Lake Alfred, Florida, according to typical industry practices [7]. Before processing, fruit were sanitized with Fruit Cleaner 395 (JBT FoodTech, Lakeland, FL) and surface-dried. Juice and an oil emulsion were extracted simultaneously with a commercial John Bean Technologies (JBT) extractor (JBT FoodTech, Lakeland, FL). The main characteristic of this extractor is that the juice and oil are extracted simultaneously. The extractor was cleaned before and after use. The oil emulsion was collected in 190 liter tanks and put into cold storage at $4^{\circ} \mathrm{C}$ for approximately 40 hours. The crude emulsion was brought to room temperature over the course of 3 hours before being refined into cold pressed orange oil.

A DeLaval table top centrifuge (DeLaval, Tumba, Sweden) specifically for oil was used to produce cold pressed orange oil. The centrifuge is equipped with a Dayton motor (Dayton Motor Company, Dayton, Texas) which operates at $1000 \times$ g. Raw material from the topmost oily portion of the emulsion was very slowly fed into the centrifuge by hand. Due to the large quantity of emulsion ( 110 liters) produced, only the top part of the emulsion which contains the most oil was fed through the centrifuge. Oil was aliquoted into vials and stored at $-20^{\circ} \mathrm{C}$ until use.

2.3. Gas Chromatography Conditions. Qualitative and quantitative gas chromatography was performed. In the qualitative experiment, cold pressed orange oils (CPOO) were analyzed by gas chromatography mass spectrometry and gas 
chromatography with a flame ionization detector (multidimensional GC/GC-MS (MDGC) by initial flame ionization detection (FID) and then "heart-cut" to an additional oven and detection by mass spectrometry (MS)) (Shimadzu GC2010 Plus Gas Chromatograph, Shimadzu QP-2010 SE Mass Spectrophotometer).

CPOO was diluted 1:5 with hexanes (Fisher HPLC grade), and approximately $1 \mathrm{~mL}$ of mixture was transferred to a brown glass sampling vial. An autoinjector (Shimadzu AOC-20i) was used to inject $2 \mu \mathrm{L}$ of sample mixture into the first GC and analyzed by FID. In the multidimensional gas chromatograph method, two ovens, an FID (Shimadzu Columbia, MD), a triple-quadrupole mass spectrometer, and a Dean's switch (Shimadzu Columbia, MD) are utilized. In a typical MDGC setup, after initial detection by the FID, compounds can be "cut" by operational software using Dean's switch to a second GC oven (with separate column and temperature programming) offering additional separation and detection by MS. Often, the purpose of MDGC is to separate insufficiently separated components. In this experiment, FID detection from the first GC was used to quantify all compounds in a first run and identification by MS in a second run cut via Dean's switching to the second GC from beginning to end. GC/GC-MS conditions are listed below.

The temperature program on the first GC was $50-250^{\circ} \mathrm{C}$ at a rate of $3^{\circ} \mathrm{C} /$ minute. The column used was an RTX-5 (Restek) column 30 meters in length, $0.25 \mathrm{~mm}$ internal diameter, and $0.25 \mu \mathrm{m}$ film thickness. Inlet temperature was $280^{\circ} \mathrm{C}$. The column flow rate was $0.71 \mathrm{~mL} /$ minute. The inlet pressure was $190.9 \mathrm{kPa}$. The FID sampling rate was 40 milliseconds; FID inlet temperature was $300^{\circ} \mathrm{C}$. The compounds were then cut to the second GC, which also had an RTX-5 column with the similar operating conditions as the first GC. The pressure in the second GC was $160.0 \mathrm{kPA}$, and the temperature program was the same as for the first GC. The column flow rate was $0.7 \mathrm{~mL} / \mathrm{min}$ and the linear velocity was $23.7 \mathrm{~cm} / \mathrm{min}$. For the MS, scan mode was used. The ionization energy was $70 \mathrm{eV}$ and the acquisition mass range was $m / z 40-400$. MS ionization was autotuned against perfluorotributylamine (PFTBA) for quality control based on Shimadzu engineering recommendations for maximum efficiency.

Qualitative compound identification by MS was performed by matching compound MS output to database entries using similarity searching of MS fragmentation patterns against multiple compound libraries. The libraries used were the National Institute of Science and Technology (Gaithersburg, MD) Mass Spectrometry Spectra Database versions 11, 11s, 14, 14s, and Flavor and Fragrance Natural and Synthetic Compounds GC/MS library from Shimadzu (Columbia, MD). Compounds of interest were considered if it had a similarity match of at least $80 \%$. However, the top match of similarity searches from "heart-cut" FID responses sent to the other RTX-5 column equivalent and GC oven by multidimensional switching were matched given delayed retention time calculations to account for flow rate through 30 meters of RTX- 5 equivalent column.

Each CPOO was analyzed in triplicate. Kovats Indices (KI) were calculated as a confirmation of identified compounds. Alkane standard measurement ranging from C6 to C35 was utilized for this purpose and detected by FID (SPEXOrganics, Metuchen, NJ). Six concentrations (4 to $66,700 \mathrm{ppm}$ ) were used to create a standard curve from the first GC by FID. Identified compounds were considered identified by LRI if the observed value was within 15 points of a value compared to reputable databases or literature [11-13].

For each compound identified, the average total peak areas between SY and AS samples were compared. If the percent difference was $\geq 20 \%$, this compound was flagged and considered for quantitative analysis. The following equation for percent difference was utilized: [(AS - SY)/(AS)] * 100, where AS is asymptomatic average total peak area and SY is symptomatic average total peak area.

Using the criteria above, fifteen compounds were ultimately chosen for quantification. These compounds were purchased as analytical standards in the highest concentration available. Dodecanal, 2-decenal, citronellal, citronellyl acetate, $\alpha$-terpinyl acetate, $\alpha$-pinene, citral, perillaldehyde, decanal, linalool, and citronellol were purchased from Sigma Aldrich (St. Louis, MO). $\beta$-Myrcene and carvone were purchased from Acros Organics (Waltham, MA). (E,E)-2,4Decadienal was purchased from Tokyo Chemical Industry (Tokyo, Japan). $\beta$-Myrcene was only available at a concentration of $\sim 90 \%$, so a correction factor was taken into account when calculating the concentration of this compound. Standard curves were used to determine concentration in parts per million ( $\mathrm{ppm})$.

2.4. Statistical Analysis. Student's $t$-tests were performed to determine if concentration of AS samples differed from SY samples based on disease stage or harvest time (early or late). Significance was set at $\alpha \leq 0.01$.

\section{Results and Discussion}

3.1. Qualitative Gas Chromatography. CPOOs from the 20152016 harvest year were evaluated by GC/GC-MS to determine volatile composition. CPOO from Early Hamlin, Late Hamlin, Early Valencia, and Late Valencia oranges were analyzed, and presumptive compound identification was performed by mass spectral match to several flavor and fragrance libraries, according to Shimadzu MDGC specifications by FID screening and identification by MS as previously described.

Forty-four compounds were identified in Early Hamlin and 46 compounds were identified in Late Hamlin by initial FID detection and cut compounds in a second analysis of the gas-liquid source through a second oven and RTX5 equivalent capillary GC column for MS identification (Table 1).

All the compounds identified in Early Hamlin were identified in Late Hamlin. Late Hamlin additionally contained trace amounts of 2,4-decadienal and 2-decenal. Forty-seven compounds were identified in Early Valencia and 46 were identified in Late Valencia (Table 2). All the compounds identified in Late Valencia were identified in Early Valencia; Early Valencia additionally contained $\delta$-cadinene. Compounds are sorted by compound retention index, which is a standard method used to tentatively identify compounds. 


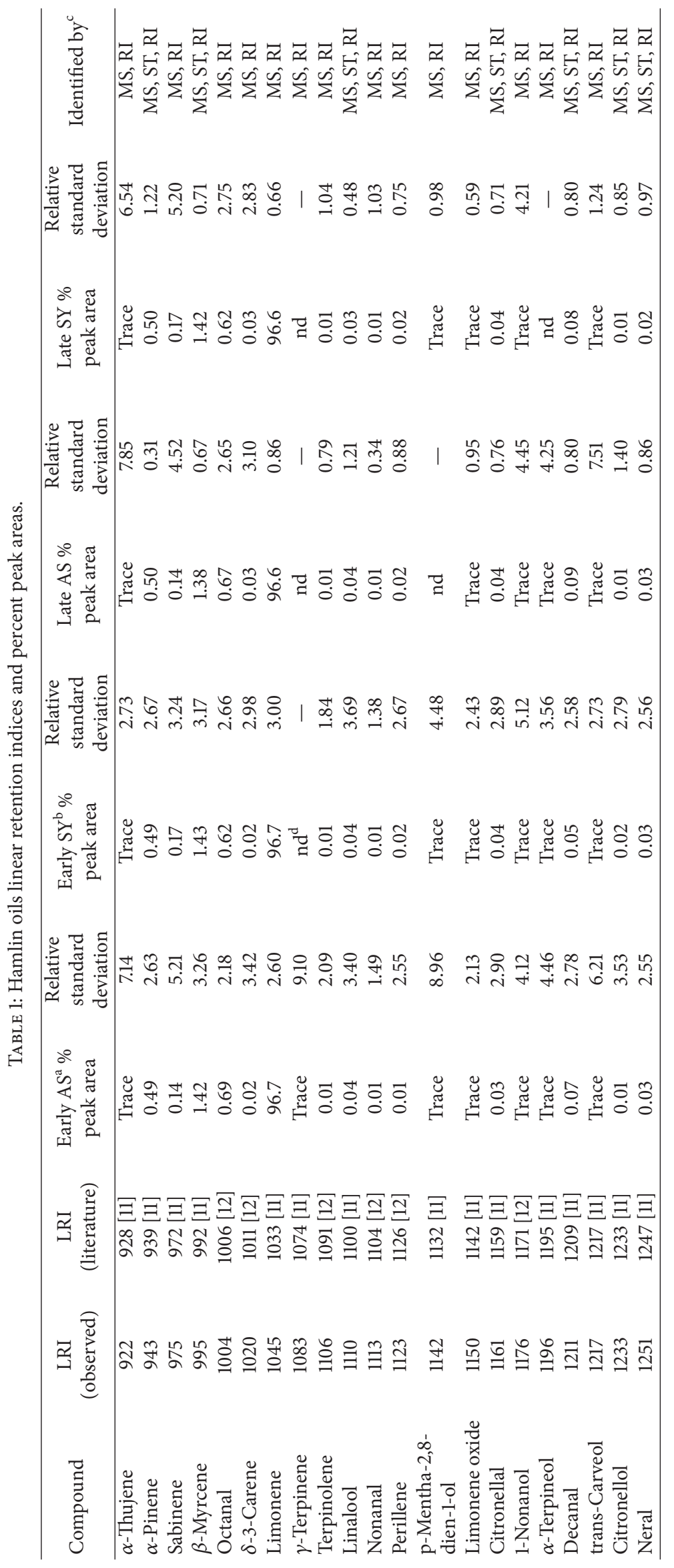




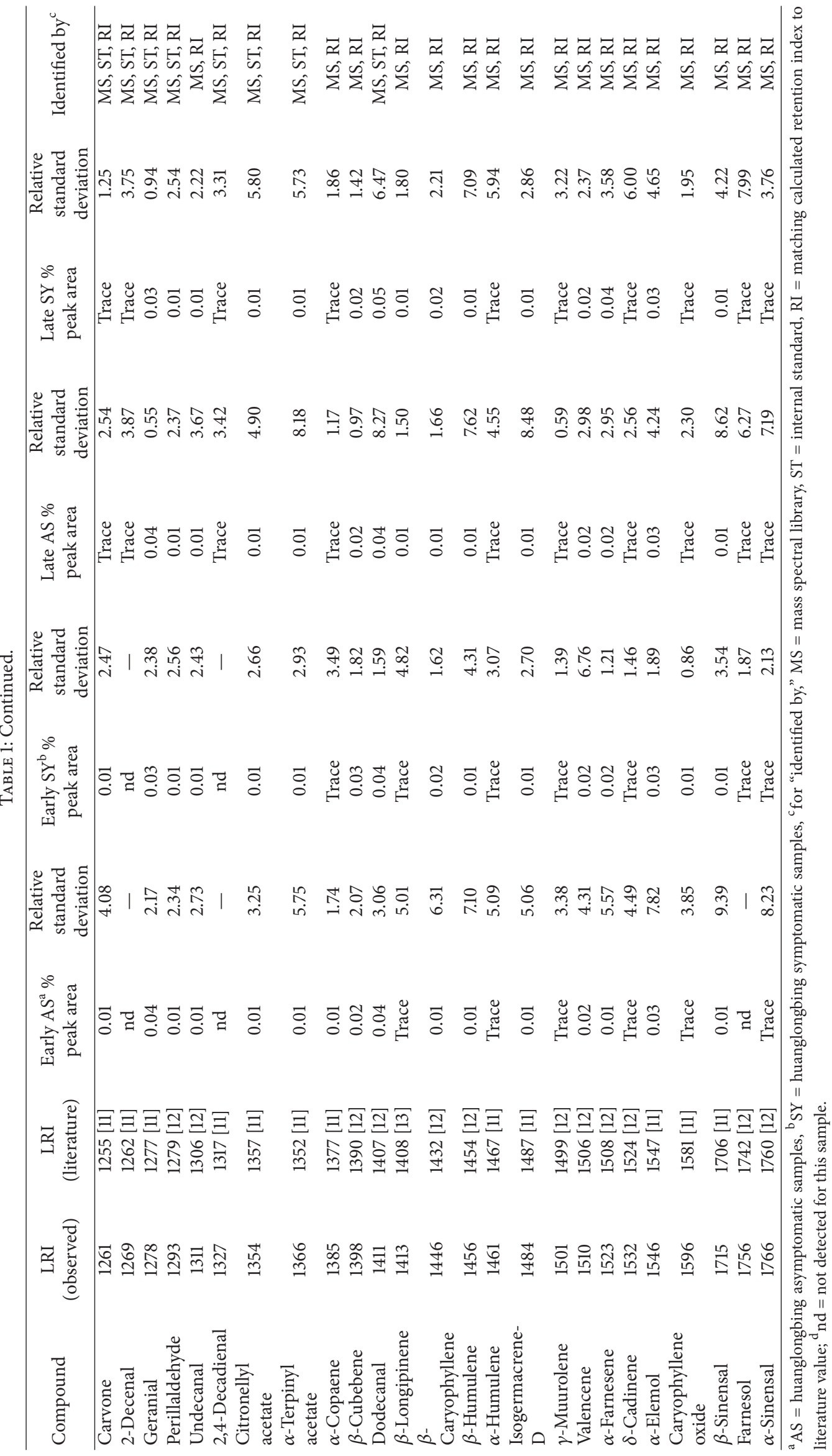




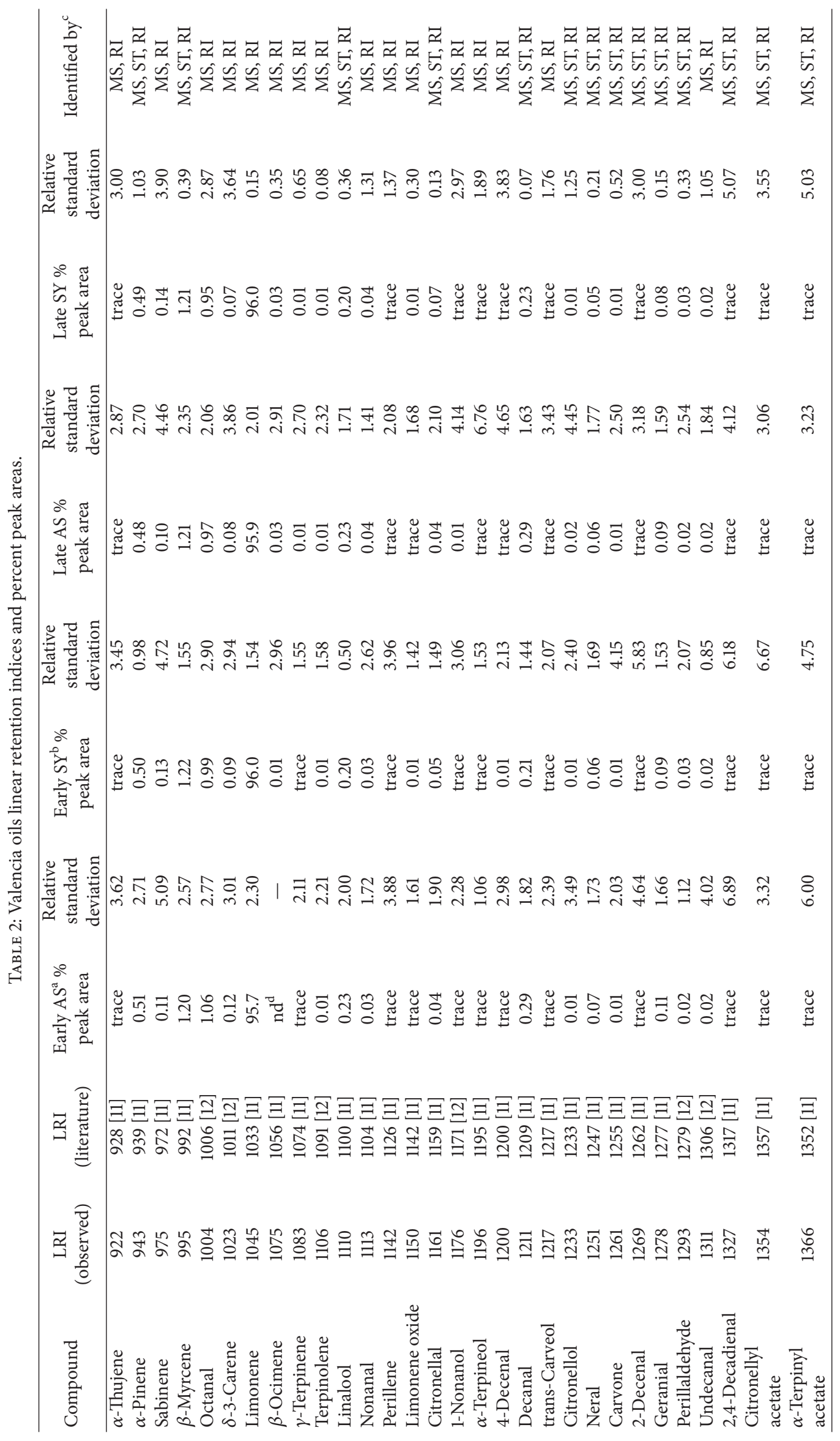




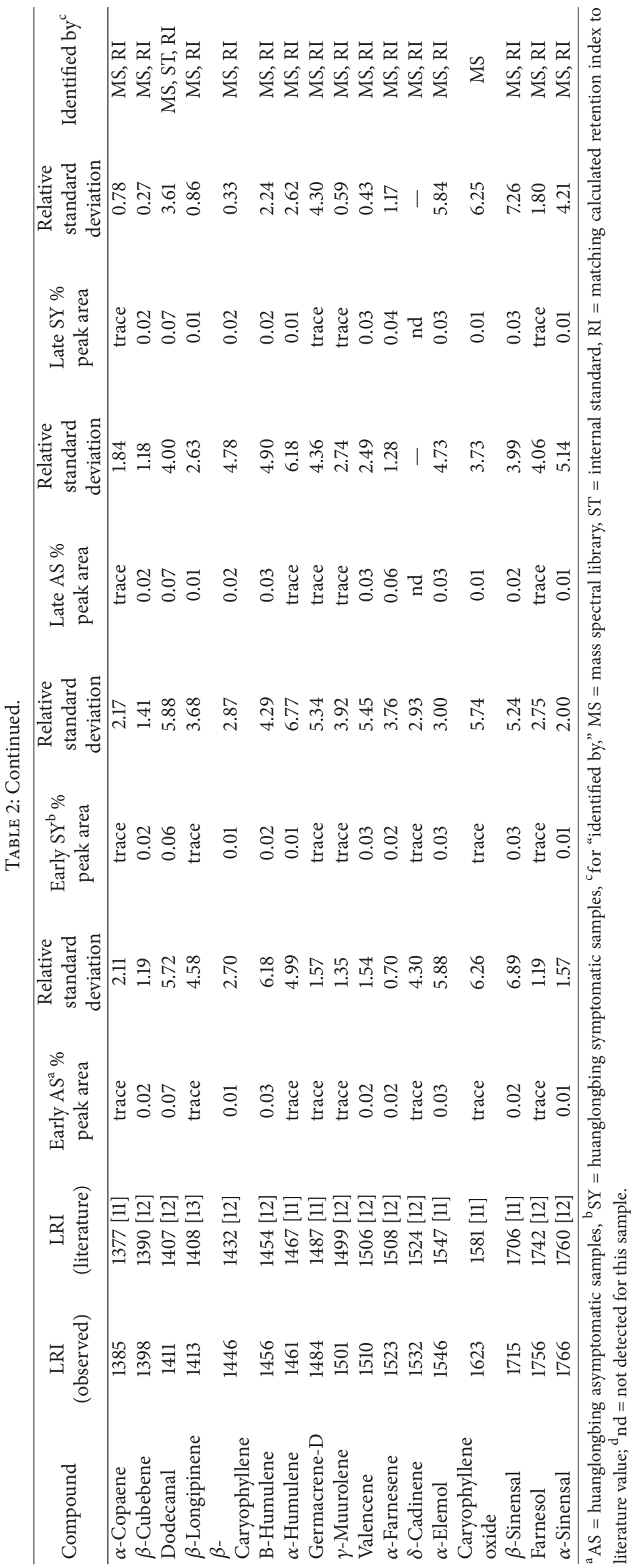


TABLE 3: Hamlin early asymptomatic versus symptomatic compound concentration.

\begin{tabular}{|c|c|c|c|c|}
\hline Compound & $\mathrm{AS}^{\mathrm{a}}$ concentration $(\mathrm{ppm})$ & $\mathrm{SY}^{\mathrm{b}}$ concentration $(\mathrm{ppm})$ & $p$ value & Difference \\
\hline$\alpha$-Pinene & 5267 & 4903 & 0.037 & $6.9 \%$ \\
\hline$\beta$-Myrcene & 12794 & 13918 & 0.089 & $7.9 \%$ \\
\hline Linalool & 660 & 486 & $0.0014^{\mathrm{c}}$ & $26.4 \%$ \\
\hline Citronellal & 506 & 601 & $0.00072^{\mathrm{c}}$ & $15.8 \%$ \\
\hline Decanal & 858 & 561 & $0.00052^{c}$ & $34.6 \%$ \\
\hline Citronellol & 129 & 141 & 0.043 & $8.5 \%$ \\
\hline Neral & 492 & 341 & $<0.0001^{c}$ & $30.6 \%$ \\
\hline Carvone & 69.9 & 60.7 & $0.0046^{\mathrm{c}}$ & $13.2 \%$ \\
\hline 2-Decenal & $\mathrm{nd}^{\mathrm{d}}$ & nd & nd & nd \\
\hline Geranial & 732 & 536 & $0.0011^{c}$ & $26.8 \%$ \\
\hline Perillaldehyde & 140 & 138 & 0.440 & $1.4 \%$ \\
\hline 2,4-Decadienal & nd & nd & nd & nd \\
\hline Citronellyl acetate & 43.5 & 58.8 & $<0.0001^{\mathrm{c}}$ & $26.0 \%$ \\
\hline$\alpha$-Terpinyl acetate & 52.8 & 65.7 & $0.00095^{\mathrm{c}}$ & $19.6 \%$ \\
\hline Dodecanal & 767 & 753 & 0.298 & $1.8 \%$ \\
\hline
\end{tabular}

${ }^{\mathrm{a}} \mathrm{AS}=$ huanglongbing asymptomatic samples; ${ }^{\mathrm{b}} \mathrm{SY}=$ huanglongbing symptomatic samples; ${ }^{\mathrm{c}}$ significant differences at $\alpha \leq 0.01$; ${ }^{\mathrm{d}}$ nd $=$ not detected.

All the compounds identified in this study have been previously identified in $\mathrm{CPOO}$, although three compounds are not commonly identified in CPOO extracted from Citrus sinensis. These three compounds are perillene (3(4-Methyl-3-pentenyl)furan), $\beta$-longifolene, and 4-decenal. The compound 4-decenal has previously been identified in orange essence oil, orange juice, Pontianak orange peel, and clementine peel [16-19]. One aspect which these four studies had in common is that 4-decenal was first identified by gas chromatography-olfactometry. Often 4-decenal is present in citrus at fairly low concentrations but is very odor active, having an odor which was called lemon and pine [19] or citrus and flower [18]. Because it is very odor active, 4-decenal is often more readily identified by gas chromatographyolfactometry than by GC-MS.

$\beta$-Longifolene has previously been identified in Citrus sinensis orange essence oil [16]. Additionally, it has been reported in Citrus sphaerocarpa peel oil, fresh squeezed orange juice of an undisclosed variety, and oil derived from Citrus sinensis flowers [20-22]. Perillene has previously been identified in Kenyan Valencia Citrus sinensis CPOO, Australian finger lime (Citrus australasica) peel oil, and Neroli (Citrus aurantium) oil [23-25]. Perillene can be produced from biochemical conversion of $\beta$-myrcene, a common constituent in orange oil [26]. It is possible that this bioconversion mechanism leads to a measurable quantity of perillene in our samples.

Qualitatively, the major compounds generally found in CPOO of Citrus sinensis (L.) Osbeck were observed in our samples, with the exception of nerol and $\beta$-elemene. The compounds 4-decenal, perillene, and $\beta$-longifolene were tentatively identified by a combination of Kovats Indices and MS library match. These compounds are not commonly identified in Citrus sinensis (L.) Osbeck oils but have each been identified in citrus multiple studies. Further research is necessary to determine if presence of these compounds is biomarkers indicative of HLB positive Citrus sinensis (L.) Osbeck oils.

3.2. Quantitative Gas Chromatography. Based on the results from the qualitative gas chromatography experiments, fifteen compounds were chosen for quantitation using GC-FID based on an indication that AS and SY samples may contain large differences in the concentration of these compounds (Tables 3-6). While 13 of the compounds were included due to suspected differences based on the qualitative studies $(\geq 20 \%$ difference in concentration between AS and SY samples), $\beta$-myrcene and $\alpha$-pinene were also included because these terpenes are found at high concentrations in CPOO and contribute to orange aroma [27]. Chromatograms from each sample can be found in Figures 1-8.

3.2.1. Effect of Disease Stage. Each of the 15 compounds was analyzed as analytical standards by GC-FID in duplicate at six concentrations to create a standard curve. Each CPOO sample was analyzed by GC-FID in triplicate, and the concentration of individual compounds was determined based on the equation derived from the standard curve. Tables 3-6 show differences between AS and SY compounds for Early Hamlin, Late Hamlin, Early Valencia, and Late Valencia, respectively.

For Early Hamlin (Table 3), significant differences $(\alpha \leq$ 0.01 ) in concentration between AS and SY oil were observed for linalool, citronellal, decanal, neral, carvone, geranial, citronellyl acetate, and $\alpha$-terpinyl acetate. The largest percent differences were for linalool (26.4\%), decanal (34.6\%), neral (30.6\%), geranial (26.8\%), and citronellyl acetate (26.0\%). Of the compounds for which there was a significant difference, AS concentration was higher for linalool, decanal, neral, carvone, and geranial. Conversely, SY concentration was significantly higher for citronellal, citronellyl acetate, and $\alpha$ terpinyl acetate. 
TABLE 4: Hamlin late asymptomatic versus symptomatic compound concentration.

\begin{tabular}{|c|c|c|c|c|}
\hline Compound & $\mathrm{AS}^{\mathrm{a}}$ concentration (ppm) & $\mathrm{SY}^{\mathrm{b}}$ concentration $(\mathrm{ppm})$ & $p$ value & Difference \\
\hline$\alpha$-Pinene & 4757 & 4655 & 0.041 & $1.9 \%$ \\
\hline$\beta$-Myrcene & 12216 & 13601 & 0.720 & $3.6 \%$ \\
\hline Linalool & 447 & 242 & $<0.0001^{\mathrm{c}}$ & $45.9 \%$ \\
\hline Citronellal & 648 & 725 & $<0.0001^{\mathrm{c}}$ & $10.6 \%$ \\
\hline Decanal & 1302 & 716 & $<0.0001^{\mathrm{c}}$ & $45.0 \%$ \\
\hline Citronellol & 128 & 123 & $0.0044^{\mathrm{c}}$ & $3.9 \%$ \\
\hline Neral & 438 & 231 & $<0.0001^{\mathrm{c}}$ & $47.2 \%$ \\
\hline Carvone & 45.6 & 33.5 & $<0.0001^{\mathrm{c}}$ & $26.5 \%$ \\
\hline 2-Decenal & $\mathrm{nd}^{\mathrm{d}}$ & nd & nd & nd \\
\hline Geranial & 650 & 386 & $<0.0001^{\mathrm{c}}$ & $40.6 \%$ \\
\hline Perillaldehyde & 122 & 115 & 0.020 & $5.7 \%$ \\
\hline 2,4-Decadienal & nd & nd & nd & nd \\
\hline Citronellyl acetate & 50.2 & 57.5 & $0.0034^{\mathrm{c}}$ & $12.7 \%$ \\
\hline$\alpha$-Terpinyl acetate & 55.1 & 62.7 & $0.0090^{c}$ & $12.1 \%$ \\
\hline Dodecanal & 875 & 795 & $0.00066^{\mathrm{c}}$ & $9.1 \%$ \\
\hline
\end{tabular}

${ }^{\mathrm{a}} \mathrm{AS}=$ huanglongbing asymptomatic samples; ${ }^{\mathrm{b}} \mathrm{SY}=$ huanglongbing symptomatic samples; ${ }^{\mathrm{c}}$ significant differences at $\alpha \leq 0.01$; ${ }^{\mathrm{d}}$ nd $=$ not detected.

TABLE 5: Valencia early asymptomatic versus symptomatic compound concentration.

\begin{tabular}{|c|c|c|c|c|}
\hline Compound & $\mathrm{AS}^{\mathrm{a}}$ concentration $(\mathrm{ppm})$ & $\mathrm{SY}^{\mathrm{b}}$ concentration $(\mathrm{ppm})$ & $p$ value & Difference \\
\hline$\alpha$-Pinene & 4881 & 4704 & 0.170 & $3.6 \%$ \\
\hline$\beta$-Myrcene & 12149 & 11525 & 0.196 & $5.1 \%$ \\
\hline Linalool & 5312 & 4274 & $0.00020^{\mathrm{c}}$ & $19.5 \%$ \\
\hline Citronellal & 575 & 740 & $<0.0001^{\mathrm{c}}$ & $22.3 \%$ \\
\hline Decanal & 3361 & 2630 & $<0.0001^{\mathrm{c}}$ & $21.8 \%$ \\
\hline Citronellol & 69.1 & 57.6 & 0.019 & $16.6 \%$ \\
\hline Neral & 1203 & 953 & $<0.0001^{c}$ & $20.8 \%$ \\
\hline Carvone & 61.3 & 47.5 & $0.00025^{\mathrm{c}}$ & $22.5 \%$ \\
\hline 2-Decenal & 35.0 & 21.9 & $0.00084^{c}$ & $27.2 \%$ \\
\hline Geranial & 1556 & 1301 & $0.00011^{\mathrm{c}}$ & $16.4 \%$ \\
\hline Perillaldehyde & 266 & 302 & $0.00058^{\mathrm{c}}$ & $11.9 \%$ \\
\hline 2,4-Decadienal & 37.8 & 27.5 & 0.064 & $27.2 \%$ \\
\hline Citronellyl acetate & 18.4 & 18.2 & 0.863 & $1.1 \%$ \\
\hline$\alpha$-Terpinyl acetate & 30.1 & 27.7 & 0.462 & $8.0 \%$ \\
\hline Dodecanal & 1180 & 1082 & $0.0013^{c}$ & $8.2 \%$ \\
\hline
\end{tabular}

${ }^{\mathrm{a}} \mathrm{AS}=$ huanglongbing asymptomatic samples; ${ }^{\mathrm{b}} \mathrm{SY}=$ huanglongbing symptomatic samples; ${ }^{\mathrm{c}}$ significant differences at $\alpha \leq 0.01$.

For Late Hamlin (Table 4), significant differences $(\alpha \leq$ $0.01)$ in concentration between AS and SY oil were observed for linalool, citronellal, decanal, citronellol, neral, carvone, geranial, citronellyl acetate, $\alpha$-terpinyl acetate, and dodecanal. The largest percent differences were for linalool (45.9\%), decanal $(45.0 \%)$, neral $(47.2 \%)$, carvone $(26.5 \%)$, and geranial $(40.6 \%)$. Of the compounds for which there was a significant difference, AS concentration was higher for linalool, decanal, citronellol, neral, carvone, geranial, and dodecanal. Conversely, SY concentration was significantly higher for citronellal, citronellyl acetate, and $\alpha$-terpinyl acetate.

For Early Valencia (Table 5), significant differences $(\alpha \leq$ 0.01 ) in concentration between AS and SY oil were observed for linalool, citronellal, decanal, citronellol, neral, carvone, 2decenal, geranial, perillaldehyde, and dodecanal. The largest percent difference was for 2-decenal (27.2\%); this was the only significant percent difference which was $\geq 25.0 \%$. Of the compounds for which there was a significant difference, AS concentration was higher for linalool, decanal, citronellol, neral, carvone, 2-decenal, geranial, and dodecanal. Conversely, SY concentration was significantly higher for citronellal and perillaldehyde.

For Late Valencia (Table 6) significant differences $(\alpha \leq$ 0.01 ) in concentration between AS and SY oil were observed for linalool, citronellal, decanal, citronellol, neral, carvone, 2decenal, geranial, perillaldehyde, 2,4-decadienal, and dodecanal. The largest percent differences were for citronellal 
TABLE 6: Valencia late asymptomatic versus symptomatic compound concentration.

\begin{tabular}{|c|c|c|c|c|}
\hline Compound & $\mathrm{AS}^{\mathrm{a}}$ concentration $(\mathrm{ppm})$ & $\mathrm{SY}^{\mathrm{b}}$ concentration $(\mathrm{ppm})$ & $p$ value & Difference \\
\hline$\alpha$-Pinene & 4936 & 4664 & 0.030 & $5.5 \%$ \\
\hline$\beta$-Myrcene & 12251 & 11791 & 0.448 & $3.8 \%$ \\
\hline Linalool & 4260 & 4548 & $0.0083^{c}$ & $6.3 \%$ \\
\hline Citronellal & 682 & 995 & $<0.0001^{\mathrm{c}}$ & $31.5 \%$ \\
\hline Decanal & 3541 & 2712 & $<0.0001^{\mathrm{c}}$ & $23.4 \%$ \\
\hline Citronellol & 134.9 & 113.7 & $<0.0001^{\mathrm{c}}$ & $15.7 \%$ \\
\hline Neral & 1007 & 876 & $0.00025^{c}$ & $13.0 \%$ \\
\hline Carvone & 81.1 & 60.3 & $<0.0001^{\mathrm{c}}$ & $25.6 \%$ \\
\hline 2-Decenal & 47.5 & 25.6 & $<0.0001^{\mathrm{c}}$ & $46.1 \%$ \\
\hline Geranial & 1350 & 1165 & $<0.0001^{\mathrm{c}}$ & $13.7 \%$ \\
\hline Perillaldehyde & 257 & 307 & $0.00011^{\mathrm{c}}$ & $16.3 \%$ \\
\hline 2,4-Decadienal & 53.2 & 33.6 & $0.00091^{\mathrm{c}}$ & $36.8 \%$ \\
\hline Citronellyl acetate & 21.8 & 20.3 & 0.144 & $6.9 \%$ \\
\hline$\alpha$-Terpinyl acetate & 35.4 & 34.1 & 0.517 & $3.7 \%$ \\
\hline Dodecanal & 1276 & 1194 & $0.00081^{\mathrm{c}}$ & $6.4 \%$ \\
\hline
\end{tabular}

${ }^{\mathrm{a}} \mathrm{AS}=$ huanglongbing asymptomatic samples; ${ }^{\mathrm{b}} \mathrm{SY}=$ huanglongbing symptomatic samples; ${ }^{\mathrm{c}}$ significant differences at $\alpha \leq 0.01$.

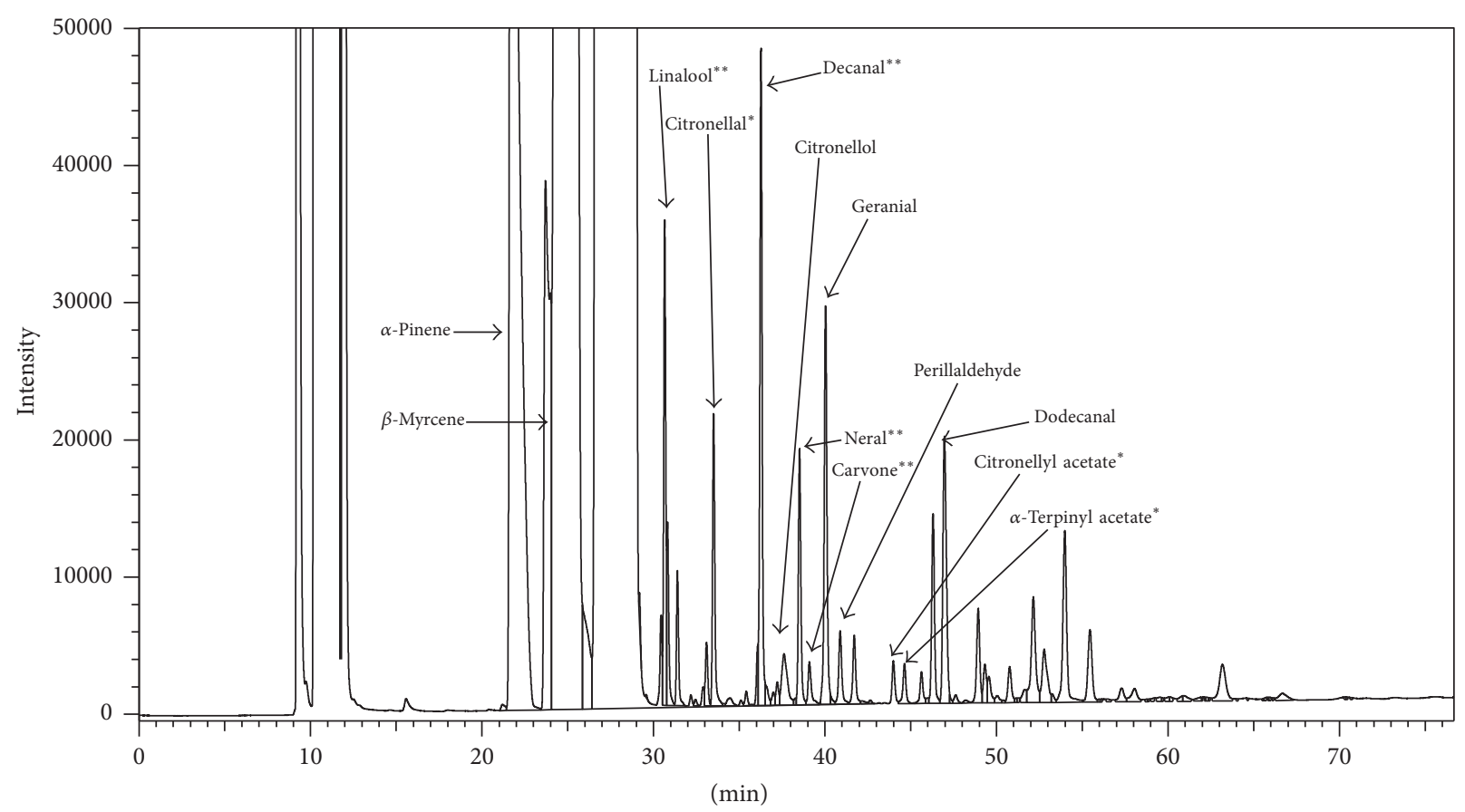

FIGURE 1: Chromatogram from Hamlin Early Asymptomatic. Note. 2-Decenal and 2,4-decadienal are not labeled on the chromatogram as they were not detected in this sample. ${ }^{*}$ Compound has lower concentration compared to HES. ${ }^{* *}$ Compound has higher concentration compared to HES.

(31.5\%), carvone (25.6\%), and 2-decenal (46.1\%). Of the compounds for which there was a significant difference, AS concentration was higher for linalool, decanal, citronellol, neral, carvone, 2-decenal, geranial, 2,4-decadienal, and dodecanal. Conversely, SY concentration was significantly higher for citronellal and perillaldehyde.
Some trends were gleaned from these results based on compound concentration and disease stage. Overall, no changes in $\alpha$-pinene and $\beta$-myrcene concentration were observed based on disease stage. Compounds for which AS oil had significantly higher concentrations were linalool, decanal, citronellol, neral, geranial, carvone, dodecanal, and 


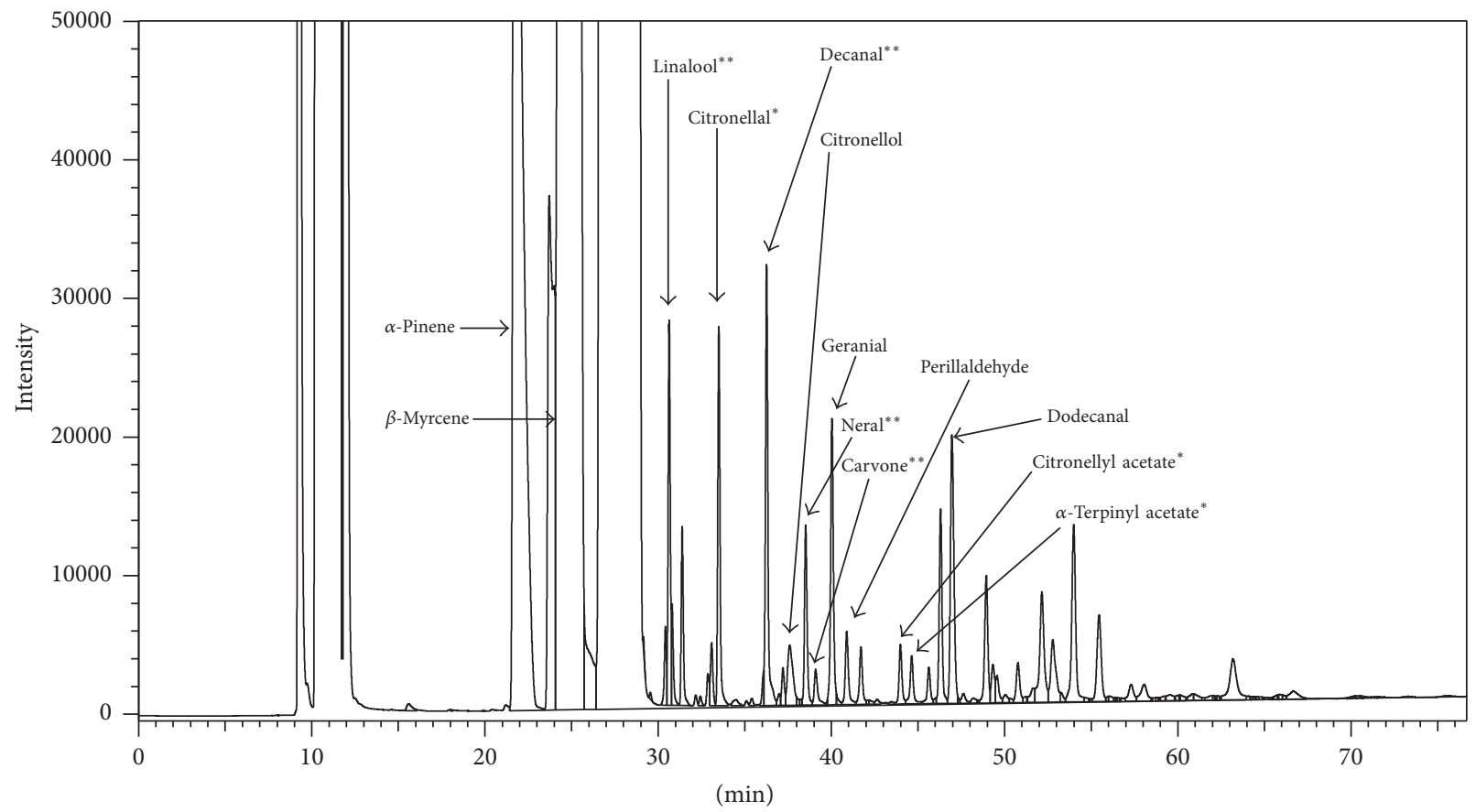

FIGURE 2: Chromatogram from Hamlin Early Symptomatic. Note. 2-Decenal and 2,4-decadienal are not labeled on the chromatogram as they were not detected in this sample. ${ }^{*}$ Compound has lower concentration compared to HEA. ${ }^{* *}$ Compound has higher concentration compared to HEA.

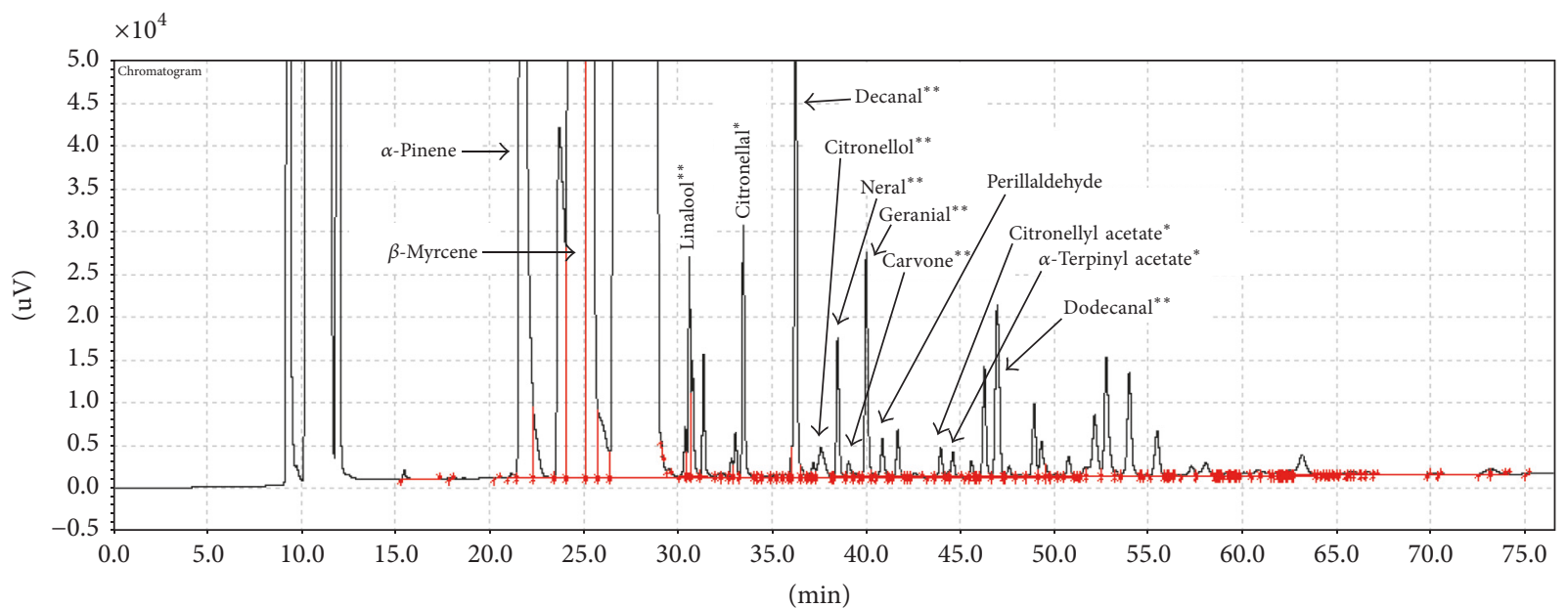

Figure 3: Chromatogram from Hamlin Late Asymptomatic. Note. While 2-decenal and 2,4-decadienal were quantifiable in this sample, they were not labeled on the chromatogram as the peaks are too small to be seen. ${ }^{*}$ Compound has lower concentration compared to HLS. ${ }^{* *}$ Compound has higher concentration compared to HLS.

2-decenal; the latter was only detectable in Valencia oil. Compounds for which SY oil had significantly higher concentration were citronellal for both Hamlin and Valencia samples, $\alpha$-terpinyl acetate and citronellyl acetate for Hamlin samples, and perillaldehyde for Valencia samples.

In HLB affected oranges both the physiology of the whole orange as well as the orange juice resemble that of less mature fruit [10]. Volatiles, including the dominant terpenoid class found in orange oil, are generally secondary metabolites.
Unlike primary metabolites, secondary metabolites do not support the primary life functions of a plant, and a dearth of secondary metabolites will not directly result in plant death. The terpenoids in orange oil, primarily d-limonene, are secondary metabolites which play roles as chemical messengers [28]. It is possible that HLB affects oranges such that as the severity of HLB increases, volatile formation via secondary metabolism is inhibited in a substantial way. Previous studies on HLB affected orange juice $[9,10]$ show 


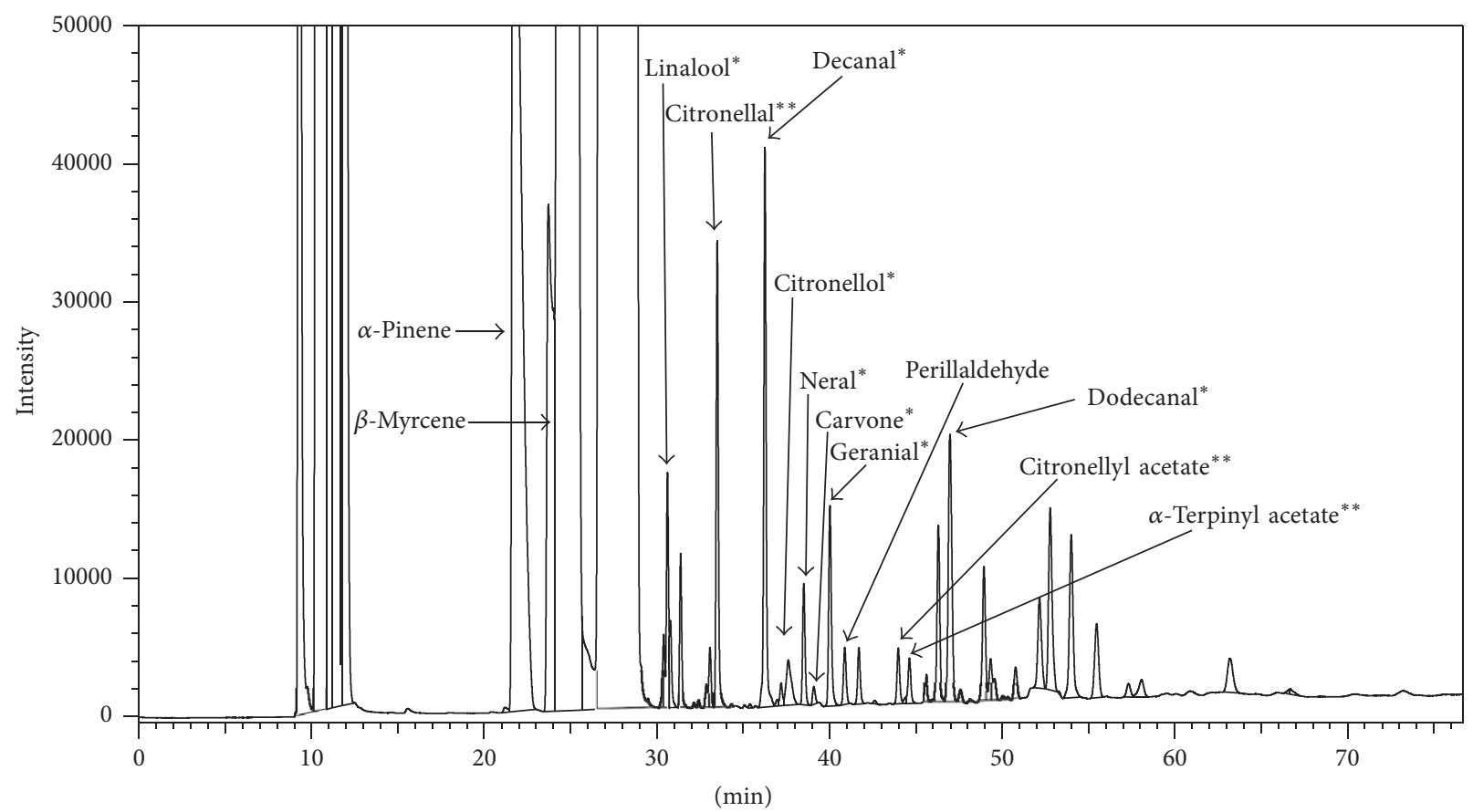

Figure 4: Chromatogram from Hamlin Late Symptomatic. Note. While 2-decenal and 2,4-decadienal were quantifiable in this sample, they were not labeled on the chromatogram as the peaks are too small to be seen. ${ }^{*}$ Compound has lower concentration compared to HLA. ** Compound has higher concentration compared to HLA.

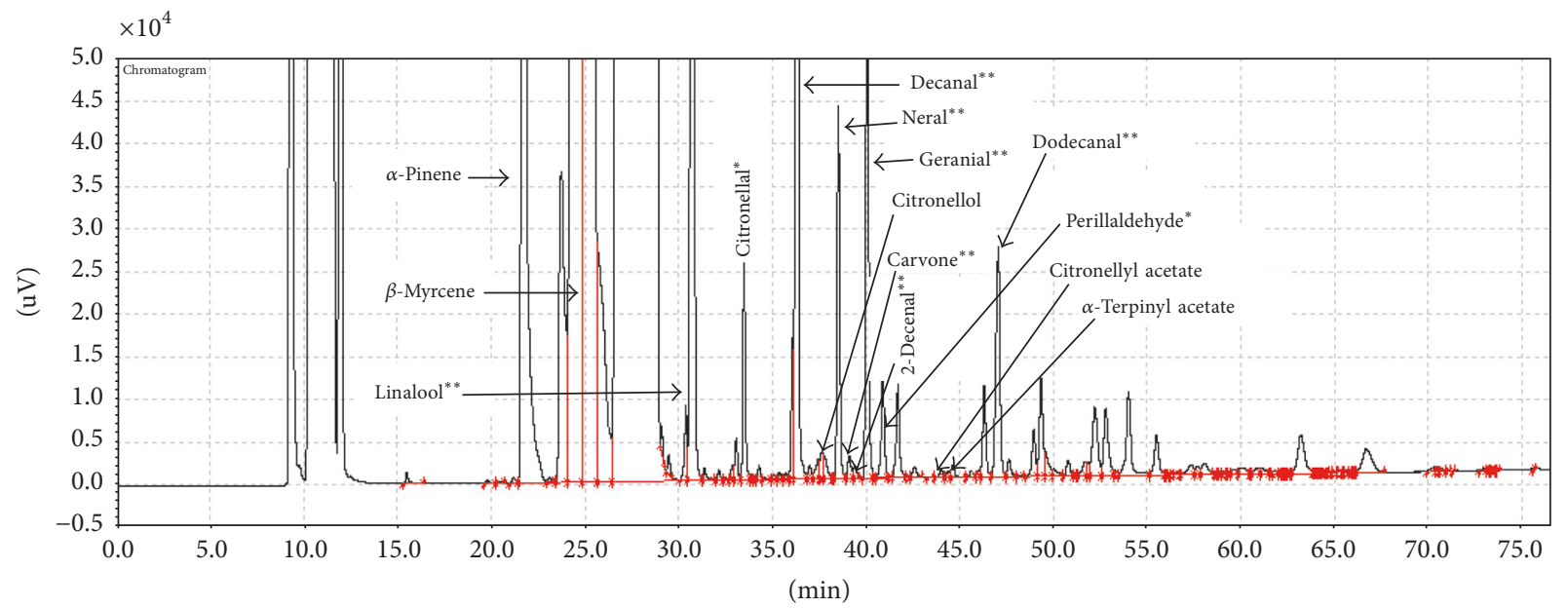

FIgURE 5: Chromatogram from Valencia Early Asymptomatic. Note. While 2,4-decadienal was quantifiable in this sample, it was not labeled on the chromatogram as the peak is too small to be seen. ${ }^{*}$ Compound has lower concentration compared to VES. ${ }^{* *}$ Compound has higher concentration compared to VES.

that overall many volatile compound concentrations decrease when oranges are HLB positive.

Dagulo et al. investigated the effects of HLB on the volatiles in orange juice [9]. In this study, control (HLB unaffected), AS, and SY Valencia juice was analyzed by GCMS to determine how HLB affects relative volatile concentrations. Of the 15 compounds studied qualitatively in our research, Dagulo et al. reported on eight of these compounds: $\alpha$-pinene, $\beta$-myrcene, decanal, linalool, citronellol, carvone, citronellyl acetate, and perillaldehyde. When comparing SY to AS juice, $\alpha$-pinene, $\beta$-myrcene, citronellyl acetate, and citronellol showed no significant differences between AS and SY juices. Our research supports the results seen concerning $\alpha$-pinene and $\beta$-myrcene, but we found that citronellol was significantly higher in AS CPOO than in SY CPOO and citronellyl acetate was significantly higher in SY CPOO than AS CPOO. Dagulo et al. found that decanal and carvone had significantly higher concentrations in AS orange juice compared to SY orange juice. These results were corroborated by our study. Dagulo et al. found linalool and perillaldehyde 


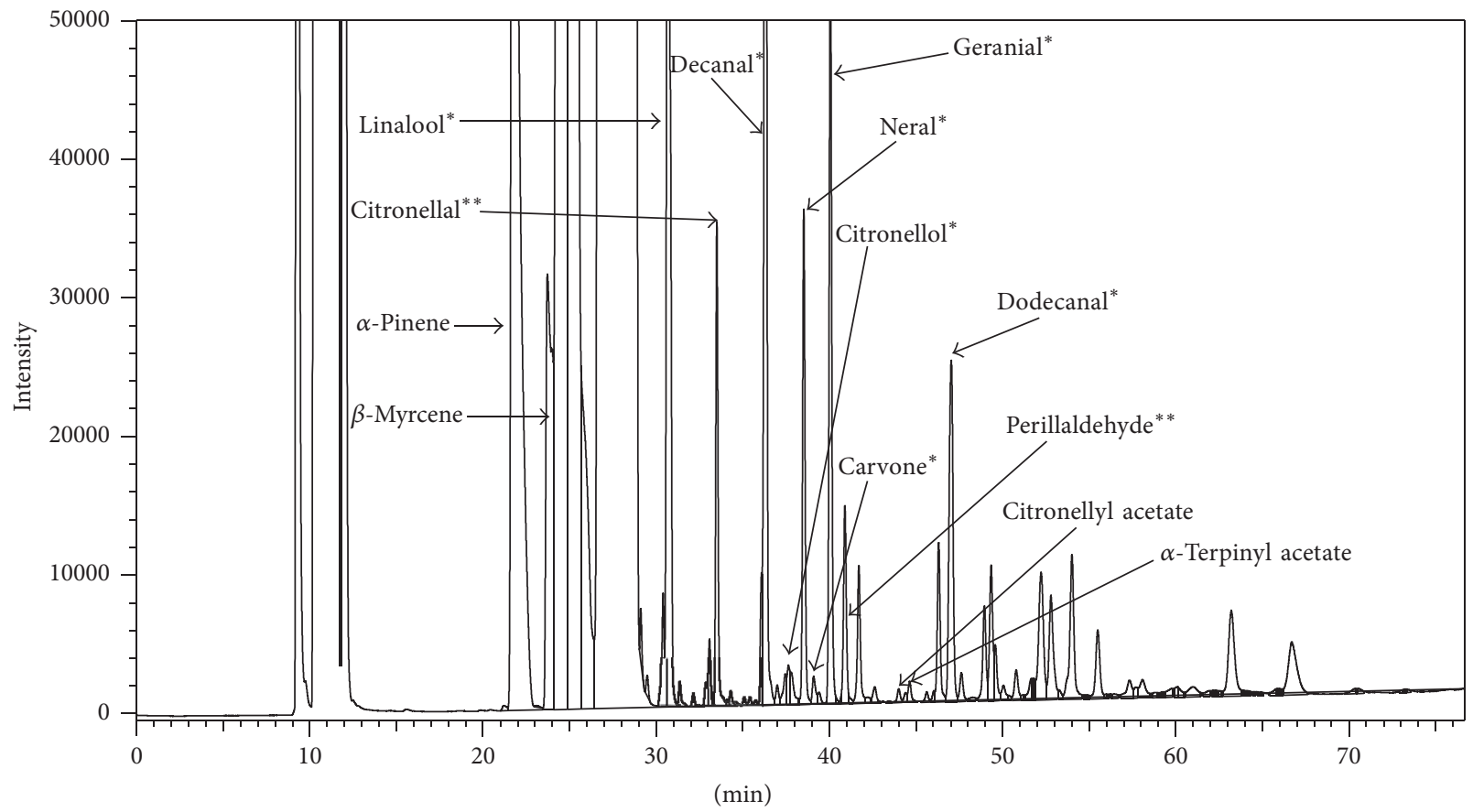

Figure 6: Chromatogram from Valencia Early Symptomatic. Note. While 2-decenal and 2,4-decadienal were quantifiable in this sample, they were not labeled on the chromatogram as the peaks are too small to be seen. ${ }^{*}$ Compound has lower concentration compared to VEA. ${ }^{* *}$ Compound has higher concentration compared to VEA.

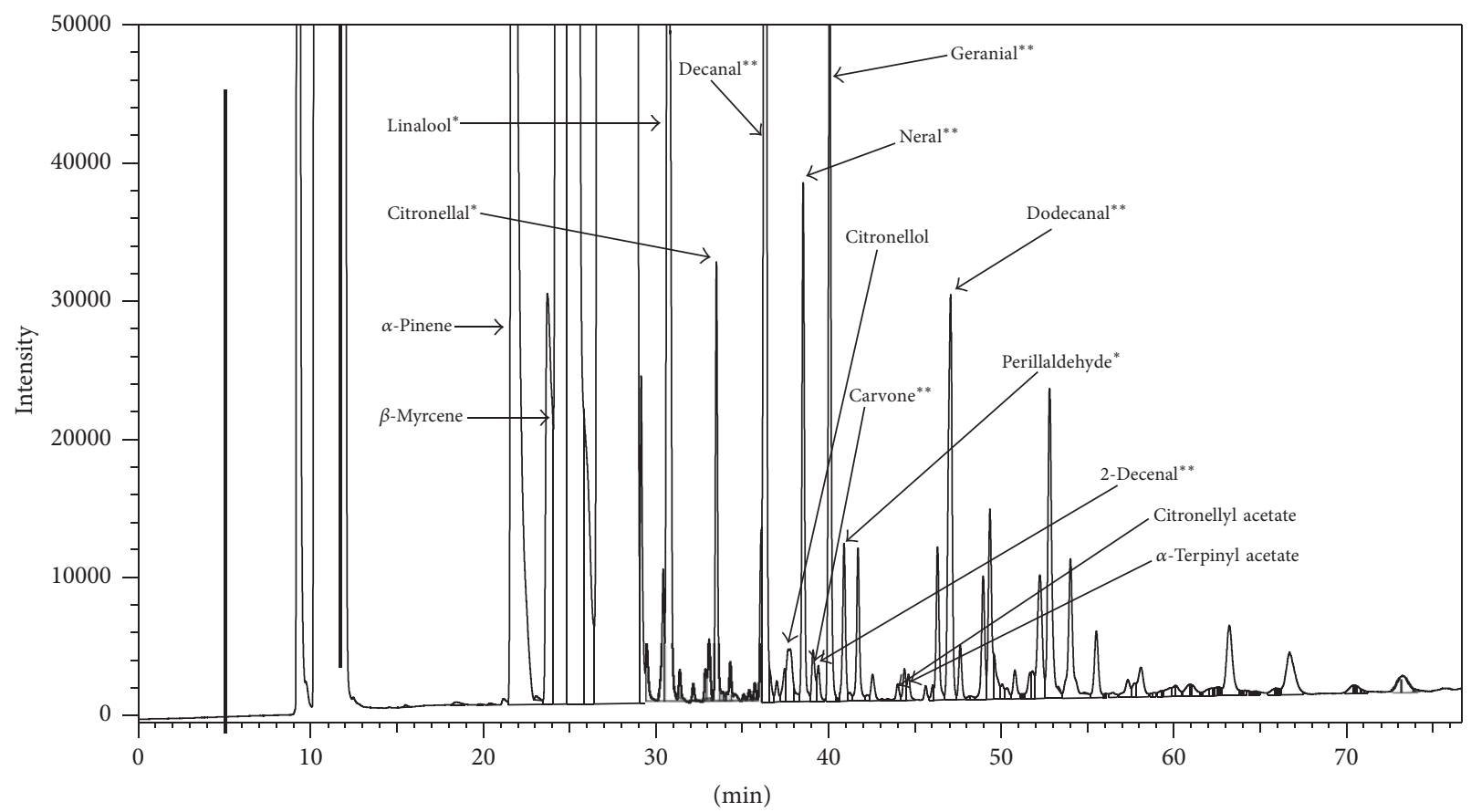

Figure 7: Chromatogram from Valencia Late Asymptomatic. Note. While 2,4-decadienal was quantifiable in this sample, it was not labeled on the chromatogram as the peak is too small to be seen. ${ }^{*}$ Compound has lower concentration compared to VLS. ${ }^{* *}$ Compound has higher concentration compared to VLS. 


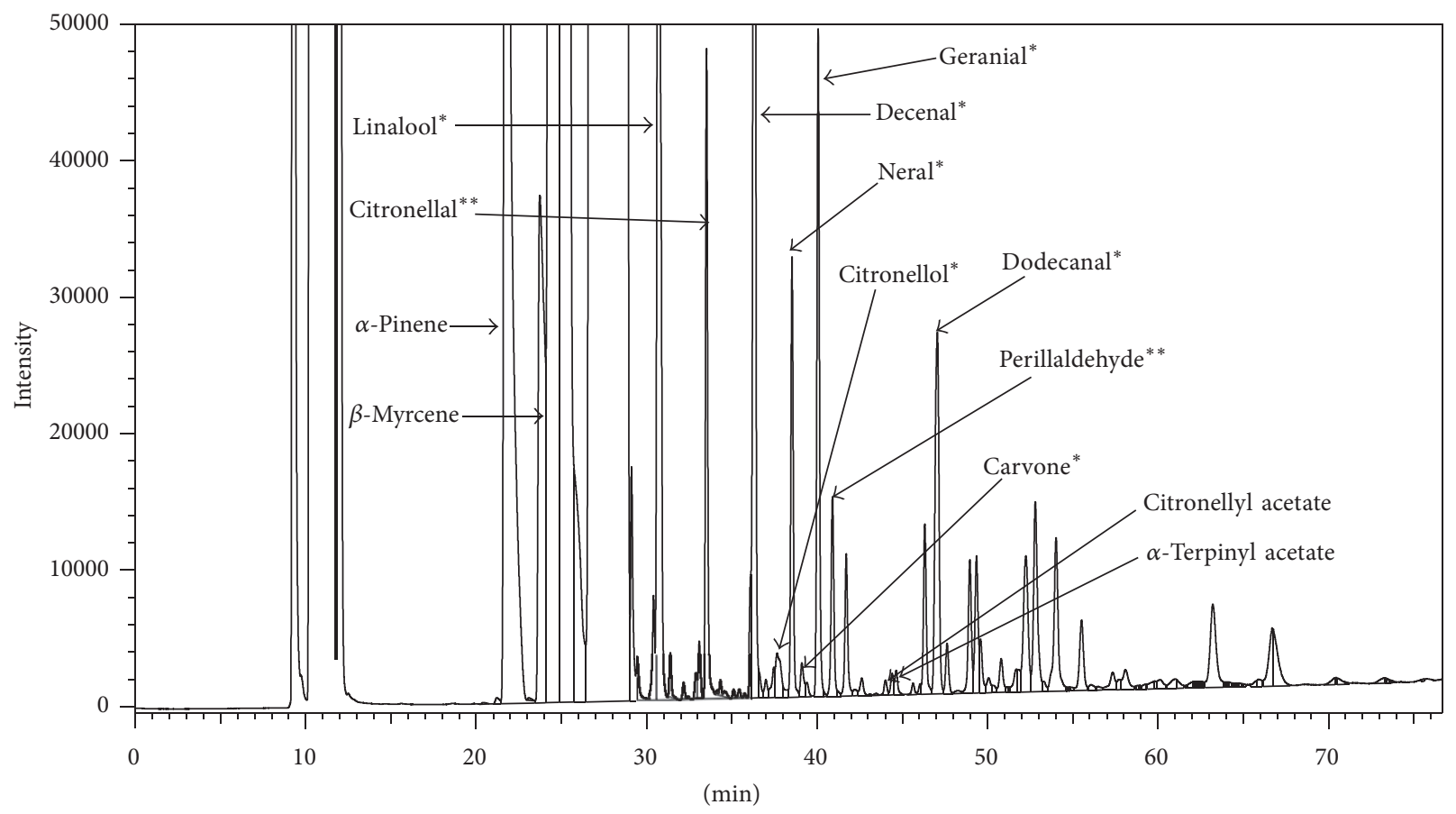

Figure 8: Chromatogram from Valencia Late Symptomatic. Note. While 2-decenal and 2,4-decadienal were quantifiable in this sample, they were not labeled on the chromatogram as the peaks are too small to be seen. ${ }^{*}$ Compound has lower concentration compared to VLA. ${ }^{* *}$ Compound has higher concentration compared to VLA.

to have significantly higher concentrations in SY orange juice compared to AS orange juice. These results were corroborated by our study for perillaldehyde but not for linalool. Overall, our observed relative volatile concentrations of $\alpha$-pinene, $\beta$-myrcene, decanal, carvone, and perillaldehyde corroborated the research performed by Dagulo et al. However, we found different results for linalool, citronellyl acetate, and citronellol. While orange juice and CPOO share many of the same volatile compounds, they are ultimately different substances. While some of the volatiles found in orange juices are derived from the peel, many of the same compounds are independently found in the essence oil, a product which is derived from orange juice. All seven compounds of interest compared to the study by Dagulo et al. can be found in essence oil [29].

The concentration increases for citronellal in both Hamlin and Valencia CPOO as well as $\alpha$-terpinyl acetate and citronellyl acetate for Hamlin CPOO and perillaldehyde for Valencia CPOO are of interest. However, no studies supporting increases in citronellal or citronellyl acetate concentrations in plants during stress situations could be found. As this is the first study on the volatiles of HLB effected cold pressed orange oil, it is possible that this is a new development specific to HLB stress in citrus. Citronellal can be produced from citral (neral + geranial) [30]. It is possible that this pathway occurs more often in HLB SY fruit than in HLB AS fruit. A higher concentration of perillaldehyde in SY oils compared to AS Valencia oils was corroborated by the results seen in Valencia orange juice [9]. $\alpha$-Terpinyl acetate has been shown to increase in concentration with water stress [31].
Additionally, while no specific data was given for $\alpha$-terpinyl acetate or citronellyl acetate, some esters were shown to increase in concentration in HLB positive orange juice [10].

Overall, it appears that, with increasing HLB severity, several important volatiles including linalool, decanal, citronellol, neral, geranial, carvone, dodecanal, and 2-decenal decrease in concentration. Citronellal in both Hamlin and Valencia samples, $\alpha$-terpinyl acetate and citronellyl acetate for Hamlin samples, and perillaldehyde in Valencia samples show higher concentrations in HLB SY samples. It is possible that these compounds increased because the stress HLB causes the orange tree. These compounds may have all increased due to shifts in biochemical pathways which occurred in trees with more severe HLB symptoms, creating greater concentrations of these volatiles.

3.2.2. Effect of Seasonality. In addition to disease stage, the effect of seasonality (early or late harvest) on the concentration of the 15 selected compounds was also analyzed. Tables 7-10 show differences between early and late season compound concentrations for Hamlin AS, Hamlin SY, Valencia AS, and Valencia SY CPOO, respectively.

For Hamlin AS (Table 7), significant differences $(\alpha \leq 0.01)$ in concentration between early and late CPOO were observed for $\alpha$-pinene, linalool, citronellal, decanal, neral, carvone, perillaldehyde, citronellyl acetate, and dodecanal. The largest percent differences were for linalool (32.3\%), decanal (34.1\%), and carvone $(34.8 \%)$. Of the compounds for which there was a significant difference, early concentration was higher for $\alpha$ pinene, linalool, neral, carvone, geranial, and perillaldehyde. 
TABLE 7: Hamlin asymptomatic early versus late compound concentration.

\begin{tabular}{|c|c|c|c|c|}
\hline Compound & Early concentration (ppm) & Late concentration (ppm) & $p$ value & Difference \\
\hline$\alpha$-Pinene & 5267 & 4757 & $0.00048^{\mathrm{a}}$ & $9.7 \%$ \\
\hline$\beta$-Myrcene & 12807 & 14133 & 0.372 & $9.3 \%$ \\
\hline Linalool & 660 & 447 & $0.00024^{\mathrm{a}}$ & $32.3 \%$ \\
\hline Citronellal & 506 & 648 & $<0.0001^{\mathrm{a}}$ & $21.9 \%$ \\
\hline Decanal & 858 & 1302 & $<0.0001^{\mathrm{a}}$ & $34.1 \%$ \\
\hline Citronellol & 129 & 128 & 0.868 & $0.78 \%$ \\
\hline Neral & 492 & 438 & $0.0025^{\mathrm{a}}$ & $11.0 \%$ \\
\hline Carvone & 69.9 & 45.6 & $<0.0001^{\mathrm{a}}$ & $34.8 \%$ \\
\hline 2-Decenal & $\mathrm{nd}^{\mathrm{b}}$ & nd & nd & nd \\
\hline Geranial & 732 & 650 & 0.029 & $11.2 \%$ \\
\hline Perillaldehyde & 140 & 122 & $0.00071^{\mathrm{a}}$ & $12.9 \%$ \\
\hline 2,4-Decadienal & nd & nd & nd & nd \\
\hline Citronellyl acetate & 43.5 & 50.2 & $0.0031^{\mathrm{a}}$ & $13.3 \%$ \\
\hline$\alpha$-Terpinyl acetate & 52.8 & 55.1 & 0.323 & $4.2 \%$ \\
\hline Dodecanal & 767 & 875 & $0.00054^{\mathrm{a}}$ & $12.3 \%$ \\
\hline
\end{tabular}

${ }^{\mathrm{a}}$ Significant differences at $\alpha \leq 0.01{ }^{\mathrm{b}}$ nd $=$ not detected.

TABLE 8: Hamlin symptomatic early versus late compound concentration.

\begin{tabular}{|c|c|c|c|c|}
\hline Compound & Early concentration (ppm) & Late concentration (ppm) & $p$ value & Difference \\
\hline$\alpha$-Pinene & 4903 & 4655 & 0.039 & $5.1 \%$ \\
\hline$\beta$-Myrcene & 13911 & 13607 & 0.602 & $2.2 \%$ \\
\hline Linalool & 486 & 242 & $<0.0001^{\mathrm{a}}$ & $50.2 \%$ \\
\hline Citronellal & 601 & 725 & $0.00011^{\mathrm{a}}$ & $17.1 \%$ \\
\hline Decanal & 561 & 716 & $0.0019^{\mathrm{a}}$ & $21.6 \%$ \\
\hline Citronellol & 141 & 123 & $0.00090^{\mathrm{a}}$ & $12.8 \%$ \\
\hline Neral & 341 & 231 & $<0.0001^{\mathrm{a}}$ & $37.5 \%$ \\
\hline Carvone & 60.7 & 33.5 & $<0.0001^{\mathrm{a}}$ & $44.8 \%$ \\
\hline 2-Decenal & $\mathrm{nd}^{\mathrm{b}}$ & nd & nd & nd \\
\hline Geranial & 536 & 386 & $<0.0001^{\mathrm{a}}$ & $28.0 \%$ \\
\hline Perillaldehyde & 138 & 115 & $0.00034^{\mathrm{a}}$ & $16.7 \%$ \\
\hline 2,4-Decadienal & nd & nd & nd & nd \\
\hline Citronellyl acetate & 58.8 & 57.5 & 0.132 & $2.2 \%$ \\
\hline$\alpha$-Terpinyl acetate & 65.7 & 62.7 & 0.035 & $4.6 \%$ \\
\hline Dodecanal & 753 & 795 & 0.013 & $5.3 \%$ \\
\hline
\end{tabular}

${ }^{\mathrm{a}}$ Significant differences at $\alpha \leq 0.01 ;{ }^{\mathrm{b}} \mathrm{nd}=$ not detected.

Conversely, late concentration was significantly higher for citronellal, citronellyl acetate, and decanal.

For Hamlin SY (Table 8), significant differences $(\alpha \leq 0.01)$ in concentration between early and late $\mathrm{CPOO}$ were observed for linalool, citronellal, decanal, citronellol, neral, carvone, geranial, and perillaldehyde. The largest percent differences were for linalool (50.2\%), neral (37.5\%), carvone (44.8\%), and geranial $(28.0 \%)$. Of the compounds for which there was a significant difference, early concentration was higher for linalool, citronellol, neral, carvone, geranial, and perillaldehyde. Conversely, late concentration was significantly higher for citronellal and decanal.

For Valencia AS (Table 9), significant differences $(\alpha \leq$ 0.01 ) in concentration between early and late $\mathrm{CPOO}$ were observed for linalool, citronellal, decanal, citronellol, neral, carvone, 2-decenal, geranial, and dodecanal. The largest significant percent differences were for citronellol (48.8\%) and 2-decenal (26.3\%). Of the compounds for which there was a significant difference, early concentration was higher for linalool, neral, and geranial. Conversely, late concentration was significantly higher for citronellal, decanal, citronellol, carvone, 2-decenal, and dodecanal.

For Valencia SY (Table 10), significant differences $(\alpha \leq$ 0.01 ) in concentration between early and late CPOO were observed for linalool, citronellal, citronellol, neral, carvone, geranial, 2,4-decadienal, and dodecanal. The largest significant percent differences were for citronellal $(25.6 \%)$ and citronellol (49.3\%). Of the compounds for which there was 
TABLE 9: Valencia asymptomatic early versus late compound concentration.

\begin{tabular}{|c|c|c|c|c|}
\hline Compound & Early concentration (ppm) & Late concentration (ppm) & $p$ value & Difference \\
\hline$\alpha$-Pinene & 4881 & 4936 & 0.660 & $1.1 \%$ \\
\hline$\beta$-Myrcene & 12149 & 12251 & 0.729 & $0.83 \%$ \\
\hline Linalool & 5312 & 4260 & $0.00032^{\mathrm{a}}$ & $19.8 \%$ \\
\hline Citronellal & 575 & 682 & $0.00021^{\mathrm{a}}$ & $15.7 \%$ \\
\hline Decanal & 3361 & 3541 & $0.0095^{\mathrm{a}}$ & $5.1 \%$ \\
\hline Citronellol & 69.1 & 134.9 & $<0.0001^{\mathrm{a}}$ & $48.8 \%$ \\
\hline Neral & 1203 & 1007 & $0.00026^{\mathrm{a}}$ & $16.3 \%$ \\
\hline Carvone & 61.3 & 81.1 & $<0.0001^{\mathrm{a}}$ & $24.4 \%$ \\
\hline 2-Decenal & 35.0 & 47.5 & $0.00029^{\mathrm{a}}$ & $26.3 \%$ \\
\hline Geranial & 1556 & 1350 & $0.00027^{\mathrm{a}}$ & $13.2 \%$ \\
\hline Perillaldehyde & 266 & 257 & 0.058 & $3.4 \%$ \\
\hline 2,4-Decadienal & 37.8 & 53.2 & 0.026 & $28.9 \%$ \\
\hline Citronellyl acetate & 18.4 & 21.8 & 0.058 & $15.6 \%$ \\
\hline$\alpha$-Terpinyl acetate & 30.1 & 35.4 & 0.137 & $15.0 \%$ \\
\hline Dodecanal & 1180 & 1276 & $0.0014^{\mathrm{a}}$ & $7.5 \%$ \\
\hline
\end{tabular}

${ }^{\mathrm{a}}$ Significant differences at $\alpha \leq 0.01$.

TABLE 10: Valencia symptomatic early versus late compound concentration.

\begin{tabular}{|c|c|c|c|c|}
\hline Compound & Early concentration (ppm) & Late concentration (ppm) & $p$ value & Difference \\
\hline$\alpha$-Pinene & 4704 & 4664 & 0.349 & $0.85 \%$ \\
\hline$\beta$-Myrcene & 11525 & 11791 & 0.691 & $2.3 \%$ \\
\hline Linalool & 4274 & 4548 & $0.0025^{\mathrm{a}}$ & $6.0 \%$ \\
\hline Citronellal & 740 & 995 & $<0.0001^{\mathrm{a}}$ & $25.6 \%$ \\
\hline Decanal & 2630 & 2712 & 0.026 & $3.0 \%$ \\
\hline Citronellol & 57.6 & 113.7 & $<0.0001^{\mathrm{a}}$ & $49.3 \%$ \\
\hline Neral & 953 & 876 & $0.0013^{\mathrm{a}}$ & $8.1 \%$ \\
\hline Carvone & 47.5 & 60.3 & $0.00018^{\mathrm{a}}$ & $21.2 \%$ \\
\hline 2-Decenal & 21.9 & 25.6 & 0.040 & $14.4 \%$ \\
\hline Geranial & 1301 & 1165 & $0.00018^{\mathrm{a}}$ & $10.5 \%$ \\
\hline Perillaldehyde & 302 & 307 & 0.177 & $1.6 \%$ \\
\hline 2,4-Decadienal & 27.5 & 33.6 & $0.0081^{\mathrm{a}}$ & $18.2 \%$ \\
\hline Citronellyl acetate & 18.2 & 20.3 & 0.061 & $10.3 \%$ \\
\hline$\alpha$-Terpinyl acetate & 27.7 & 34.1 & 0.031 & $18.8 \%$ \\
\hline Dodecanal & 1082 & 1194 & $0.00025^{\mathrm{a}}$ & $9.6 \%$ \\
\hline
\end{tabular}

${ }^{\text {a }}$ Significant differences at $\alpha \leq 0.01$.

a significant difference, early concentration was higher for neral and geranial. Conversely, late concentration was significantly higher for linalool, citronellal, citronellol, carvone, 2,4decadienal, and dodecanal.

Some trends were gleaned from these results based on compound concentration and seasonality (early or late harvest). Overall, $\alpha$-pinene, $\beta$-myrcene, citronellyl acetate, and $\alpha$-terpinyl acetate showed few or no changes based on harvest time. Compounds for which early CPOO had significantly higher concentrations were linalool, neral, geranial, carvone in Hamlin samples, and perillaldehyde in Valencia samples. Compounds for which Late CPOO had significantly higher concentrations were citronellal, decanal, dodecanal, citronellol in Hamlin samples, and carvone in Valencia samples.
To assist in explaining these results, the literature was investigated to determine what effect harvest time (early or late) could have on volatile concentrations in CPOO. Attaway et al. studied the terpenes in various citrus oils month-bymonth over the course of one season [32]. The last month surveyed in this study for Hamlin oranges was December. Maturity of oranges can vary year to year, and it can be assumed that December would correspond similarly to late season oranges in our study and that October or November would correspond to early season oranges, as early season fruit was generally harvested 6-8 weeks before late season fruit for our research. Attaway et al. showed that $\alpha$-pinene and $\beta$-myrcene either decreased slightly or remain unchanged (depending on whether October or November is considered 
TABLE 11: Hamlin peak area comparison to the literature data.

\begin{tabular}{|c|c|c|c|c|c|}
\hline Compound & AS $\%$ area & SY $\%$ area & Literature $\%$ area (Mitiku) & 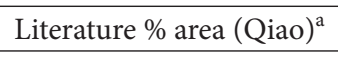 & Literature $\%$ area (Mondello) ${ }^{\mathrm{b}}$ \\
\hline$\alpha$-Pinene & 0.50 & 0.50 & 0.41 & 0.76 & 0.64 \\
\hline$\beta$-Myrcene & 1.40 & 1.42 & 1.77 & 1.88 & 2.03 \\
\hline Linalool & 0.04 & 0.03 & 0.12 & 0.92 & 0.30 \\
\hline Citronellal & 0.03 & 0.04 & 0.01 & 0.06 & 0.04 \\
\hline Decanal & 0.08 & 0.07 & 0.10 & 0.21 & 0.17 \\
\hline Citronellol & 0.01 & 0.01 & trace & $\mathrm{nr}^{\mathrm{c}}$ & $\mathrm{nr}$ \\
\hline Neral & 0.03 & 0.02 & 0.04 & 0.06 & 0.06 \\
\hline Carvone & Trace & Trace & $\mathrm{nr}$ & $\mathrm{nr}$ & $\mathrm{nr}$ \\
\hline 2-Decenal & Trace & Trace & $\mathrm{nr}$ & $\mathrm{nr}$ & $\mathrm{nr}$ \\
\hline Geranial & 0.04 & 0.04 & 0.08 & 0.11 & 0.13 \\
\hline Perillaldehyde & 0.01 & 0.01 & Trace & 0.03 & Trace \\
\hline 2,4-Decadienal & Trace & Trace & Trace & $\mathrm{nr}$ & $\mathrm{nr}$ \\
\hline Citronellyl acetate & Trace & Trace & Trace & 0.01 & 0.01 \\
\hline$\alpha$-Terpinyl acetate & Trace & Trace & Trace & $\mathrm{nr}$ & $\mathrm{nr}$ \\
\hline Dodecanal & 0.04 & 0.05 & 0.01 & 0.03 & Trace \\
\hline
\end{tabular}

${ }^{\mathrm{a}}$ Chinese variety Jinchen Citrus sinensis (L.) Osbeck; ${ }^{\mathrm{b}}$ Italian Citrus sinensis (L.) Osbeck; ${ }^{\mathrm{c}} \mathrm{nr}=$ not reported.

"early") from early to late season. Linalool and geranial either increased or remained the same (depending on whether October or November is considered "early") from early to late season. Our data corroborated the concentrations of $\alpha$-pinene and $\beta$-myrcene remaining the same but did not corroborate an increase in the concentration of linalool or geranial as the season progressed.

Kesterson et al. found that the aldehyde content in Valencia CPOO increased from February to March [6]. These were the months our early and late season Valencia oranges were harvested. As decanal is the primary aldehyde in orange oil [6], an increase in aldehyde content for late season fruit corroborates the data shown by Kesterson et al. Overall, there is a lack of published literature to determine if the changes in volatile concentration during different harvest months observed in our study are similar or different than what would be expected before the onset of HLB.

3.3. Comparison to the Literature. As no control or HLB unaffected fruit was available at the time of this study, the percent areas for compounds found in AS and SY Hamlin and Valencia CPOO were compared to three published studies on orange oils. Since few studies report the effects of seasonality, early and late percent areas measured in triplicate were averaged, resulting in a single value for each compound for both Hamlin and Valencia fruit.

While several studies [33-37] have reported on the relative concentration of compounds in Florida CPOO, these studies tend to be older, somewhat outdated, and incomplete. Therefore, studies using Citrus sinensis (L.) Osbeck fruit from other countries were used for this comparison for a more complete, modern perspective. Mitiku et al. used both Hamlin and Valencia oranges from Ethiopia [38]. Qiao et al. [27] used Chinese Jinchen oranges, while Mondello et al. [39] used Italian oranges. For comparison to the latter two studies, the same literature values are used in both the Hamlin and Valencia tables, since Hamlin and Valencia varieties were not used in these two studies. Although we could calculate percent peak area to $0.0001 \%$ based on the GC-FID output, it is customary in literature to report any concentration less than $0.01 \%$ as "trace"; therefore, this methodology is utilized in Tables 11 and 12.

Based on the three literature studies presented, in Hamlin CPOO (Table 11), the concentrations of linalool, decanal, neral, and geranial are low in comparison to literature values. The concentration of dodecanal is high. Especially notable is the linalool content, which is approximately 10 times less than the average concentration seen in the three literature studies. It should be noted that Florida Hamlin CPOO has never been considered as high quality AS Valencia CPOO and was often not collected during orange juice processing [6]. The geranial deficit is also notable, with the content being 2.5 times less than the literature average. Dodecanal increased 2.3 times compared to the two reported literature concentrations. The deficits in decanal (2.1 times less) and neral (2.1 times less) and the increase in dodecanal are not as severe as the other changes yet are still notable.

Valencia CPOO also showed notable changes compared to literature CPOO concentrations. Linalool (2.2 times less) had a notably lower concentration compared to the literature values. Citronellol and dodecanal (2.8 times more) had notably higher concentrations. Citronellol is generally either found in only trace quantities or is not quantifiable in CPOO, so the exact increase in the concentration of citronellol compared to literature values could not be determined. Geranial had a slightly lower (1.4 times less) and decanal a slightly higher (1.4 times more) concentration than the literature averages.

Both linalool and geraniol are formed from the precursor geranyl diphosphate [40]. Geraniol, in turn, can be transformed either to citral (neral + geranial) or citronellol. Citronellol transformation from geraniol may increase 
TABLE 12: Valencia peak area comparison to the literature data.

\begin{tabular}{|c|c|c|c|c|c|}
\hline Compound & AS $\%$ area & SY $\%$ area & Literature $\%$ area (Mitiku) & 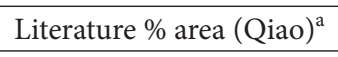 & Literature $\%$ area (Mondello) $^{\mathrm{b}}$ \\
\hline$\alpha$-Pinene & 0.50 & 0.50 & 0.35 & 0.76 & 0.64 \\
\hline$\beta$-Myrcene & 1.21 & 1.21 & 1.79 & 1.88 & 2.03 \\
\hline Linalool & 0.25 & 0.22 & 0.35 & 0.92 & 0.30 \\
\hline Citronellal & 0.04 & 0.06 & 0.03 & 0.06 & 0.04 \\
\hline Decanal & 0.29 & 0.22 & 0.16 & 0.21 & 0.17 \\
\hline Citronellol & 0.02 & 0.01 & Trace & $\mathrm{nr}^{\mathrm{c}}$ & $\mathrm{nr}$ \\
\hline Neral & 0.07 & 0.05 & 0.09 & 0.06 & 0.06 \\
\hline Carvone & Trace & Trace & $\mathrm{nr}$ & $\mathrm{nr}$ & $\mathrm{nr}$ \\
\hline 2-Decenal & Trace & Trace & $\mathrm{nr}$ & $\mathrm{nr}$ & $\mathrm{nr}$ \\
\hline Geranial & 0.10 & 0.09 & 0.16 & 0.11 & 0.13 \\
\hline Perillaldehyde & 0.02 & 0.03 & Trace & 0.03 & Trace \\
\hline 2,4-Decadienal & Trace & Trace & Trace & $\mathrm{nr}$ & $\mathrm{nr}$ \\
\hline Citronellyl acetate & Trace & Trace & Trace & 0.01 & 0.01 \\
\hline$\alpha$-Terpinyl acetate & Trace & Trace & Trace & $\mathrm{nr}$ & $\mathrm{nr}$ \\
\hline Dodecanal & 0.07 & 0.07 & 0.02 & 0.03 & Trace \\
\hline
\end{tabular}

${ }^{\mathrm{a}}$ Chinese variety Jinchen Citrus sinensis (L.) Osbeck; ${ }^{\mathrm{b}}$ Italian Citrus sinensis (L.) Osbeck; ${ }^{\mathrm{c}} \mathrm{nr}=$ not reported.

during plant stress [41]. Additionally, $\alpha$-terpinyl acetate can be derived from linalool [26]. During stress, certain volatile compounds can increase in concentration. Stress related volatile concentration change has not been studied in direct relation to $\mathrm{HLB}$, so other forms of stress are considered. Water stress has been shown to increase the concentration of citronellol in aromatic grasses [41] and dodecanal in tea [42]. It is possible that stress from HLB causes oranges to increase production of citronellol and dodecanal. Overall, when compared to historical results, our samples show a large concentration deficit in linalool, small deficits in neral and geranial, and increases in citronellol and $\alpha$-terpinyl acetate.

\section{Conclusions}

This study illuminated some of the effects huanglongbing has on the quality of cold pressed orange oil. The only compounds identified which are not normally identified in cold pressed orange oil are $\beta$-longifolene, perillene, and 4decenal. These compounds have all been previously identified in other orange products. It is possible that $\beta$-longifolene, perillene, and 4-decenal are biomarkers for huanglongbing, but further research is necessary for confirmation. Nerol and $\beta$-elemene are commonly reported in cold pressed orange oil but were not found in our samples. $\beta$-Elemene may have coeluted with $\beta$-cubebene. Nerol may have coeluted with citronellol or may not have been present.

Results showed that, based on disease stage, $\alpha$-pinene and $\beta$-myrcene showed few changes in concentration. Linalool, decanal, citronellol, neral, geranial, carvone, dodecanal, and 2-decenal (only detectable in Valencia) had higher concentrations in asymptomatic samples compared to symptomatic samples. Perillaldehyde in Valencia oil, $\alpha$-terpinyl acetate, and citronellyl acetate in Hamlin oil and citronellal in both showed higher concentrations in symptomatic than asymptomatic samples. It is possible that the biochemical pathways which form volatiles in orange oils are disrupted by huanglongbing, causing some compounds to change concentration based on the severity of huanglongbing infection. Concentrations of several important compounds including linalool, geranial, and neral were significantly lower than what is typically seen in the literature while dodecanal and citronellol had increased concentrations. Future studies on huanglongbing should focus on the concentrations of these five volatiles. There are additional differences based on harvest time and harvest year, so it is important to keep in mind that there are more effects than merely disease stage at play when differences in physiochemical properties are noted.

\section{Conflicts of Interest}

The authors declare no conflicts of interest.

\section{References}

[1] J. M. Bove, "Huanglongbing: A destructive, newly-emerging, century-old disease of citrus," Journal of Plant Pathology, vol. 88, no. 1, pp. 7-37, 2006.

[2] J. V. Da Graca, “Citrus greening disease," Annual review of phytopathology. Vol. 29, pp. 109-136, 1991.

[3] A. W. Hodges and T. H. Spreen, "Economic impacts of citrus greening (HLB) in Florida, 2006/2007- 2010/2011," in Electronic Data Information Source (EDIS) FE903, University of Florida, Gainesville, FL, USA, 2012.

[4] J. W. Kesterson and R. J. Braddock, "Citrus peel oils," in ByProducts and Specialty Products of Florida Citrus, University of Florida Instructional Food Agricultural Bulletin 784, pp. 38-58, 1976.

[5] S. C. Hood, "Relative oil yield of florida oranges," Journal of Industrial and Engineering Chemistry, vol. 8, no. 8, pp. 709-711, 1916.

[6] J. W. Kesterson, R. Hendrickson, and R. J. Braddock, "Cold pressed oil of orange," in Florida Citrus Oils, University of 
Florida Instructional Food Agricultural Bulletin 749, pp. 29-59, 1971.

[7] R. J. Braddock, "Essential oils and essences," in Handbook of Citrus By-Products and Processing Technology, pp. 149-175, John Wiley and Sons, New York, NY, USA, 1999.

[8] T. Pak, "Add-back components-Volatile flavours and floating pulp," in The Orange Book, Pyramid Communications AB, pp. 131-142, Ruter Press, 1998.

[9] L. Dagulo, M. D. Danyluk, T. M. Spann et al., "Chemical Characterization of Orange Juice from Trees Infected with Citrus Greening (Huanglongbing)," Journal of Food Science, vol. 75, no. 2, pp. C199-C207, 2010.

[10] E. Baldwin, A. Plotto, J. Manthey et al., "Effect of liberibacter infection (Huanglongbing disease) of citrus on orange fruit physiology and fruit/fruit juice quality: Chemical and physical analyses," Journal of Agricultural and Food Chemistry, vol. 58, no. 2, pp. 1247-1262, 2010.

[11] T. Acree and H. Arn, "Flavornet and human odor space," 2004, http://www.flavornet.org/index.html.

[12] University of Florida, "Citrus flavor database," 2006, http:// www.crec.ifas.ufl.edu/crec_websites/Rouseff/Website2002/ Subpages/database_f_Frameset.shtml.

[13] C.-Z. Wang, Y. Su, D. Li, B. Cai, and Y.-L. Guo, "Analysis of volatile organic compounds from dendranthema indicum var. Aromaticum by headspace gas chromatography-mass spectrometry and accurate mass measurement," Analytical Letters, vol. 43, no. 15, pp. 2297-2310, 2010.

[14] D. S. Achor, E. Etxeberria, N. Wang, S. Y. Folimonova, K. R. Chung, and L. G. Albrigo, "Sequence of anatomical symptom observations in citrus affected with huanglongbing disease," Plant Pathology, vol. 9, no. 2, pp. 56-64, 2010.

[15] H. Browning, "Citrus disease solutions status of hlb in florida: fundecitrus grower discussion," Citrus Research and Development Foundation Incorporated, 2015, http://www .fundecitrus.com.br/pdf/palestras/HLBZnaZFlridaZ-ZHaroldZBrowning.pdf.

[16] Á. Högnadóttir and R. L. Rouseff, "Identification of aroma active compounds in orange essence oil using gas chromatography-olfactometry and gas chromatography-mass spectrometry," Journal of Chromatography A, vol. 998, no. 1-2, pp. 201-211, 2003.

[17] K. Mahattanatawee, R. Rouseff, M. F. Valim, and M. Naim, "Identification and aroma impact of norisoprenoids in orange juice," Journal of Agricultural and Food Chemistry, vol. 53, no. 2, pp. 393-397, 2005.

[18] A. Fischer, W. Grab, and P. Schieberle, "Characterisation of the most odour-active compounds in a peel oil extract from Pontianak oranges (Citrus nobilis var. Lour. microcarpa Hassk.)," European Food Research and Technology, vol. 227, no. 3, pp. 735744, 2008.

[19] M. G. Chisholm, J. A. Jell, and D. M. Cass Jr., "Characterization of the major odorants found in the peel oil of Citrus reticulata Blanco cv. Clementine using gas chromatographyolfactometry," Flavour and Fragrance Journal, vol. 18, no. 4, pp. 275-281, 2003.

[20] N. T. M. Tu, Y. Onishi, H.-S. Choi et al., "Characteristic odor components of Citrus sphaerocarpa Tanaka (Kabosu) coldpressed peel oil," Journal of Agricultural and Food Chemistry, vol. 50, no. 10, pp. 2908-2913, 2002.

[21] G. Schmutzer, V. Avram, F. Covaciu et al., "Study of flavour compounds from orange juices by HS-SPME and GC-MS," in
Proceedings of the 9th International Conference on Processes in Isotopes and Molecules, PIM 2013, pp. 79-84, September 2013.

[22] D. I. Hamdan, M. E. Mohamed, R. H. Abdulla, S. M. Mohamed, and A. M. El-Shazly, "Anti-inflammatory, insecticidal, and antimicrobial activities and chemical composition of the essential oils of different plant organs from naval orange (Citrus sinensis (L.) Osbeck var. Malesy) grown in Egypt," Journal of Medicinal Plants Research, vol. 7, pp. 1204-1215, 2013.

[23] S. M. Njoroge, H. Koaze, P. N. Karanja, and M. Sawamura, "Essential oil constituents of three varieties of Kenyan sweet oranges (Citrus sinensis)," Flavour and Fragrance Journal, vol. 20, no. 1, pp. 80-85, 2005.

[24] E. Delort and A. Jaquier, "Novel terpenyl esters from Australian finger lime (Citrus australasica) peel extract," Flavour and Fragrance Journal, vol. 24, no. 3, pp. 123-132, 2009.

[25] M. H. Boelens and A. Oporto, "Natural isolates from Seville bitter orange tree," Perfumer and Flavorist, vol. 16, no. 6, pp. 2-7, 1991.

[26] U. Krings, S. Krugener, S. Rinne, and R. G. Berger, "Bioconversion of $\beta$-myrcene to perillene- Metabolites, pathways, and enzymes," Expression of Multidisciplinary Flavour Science, https://home.zhaw.ch/ yere/pdf/Teil83\%20-\% 20Expression\%20of\%20Multidisciplinary.pdf.

[27] Y. Qiao, J. X. Bi, Y. Zhang et al., "Characterization of aroma active compounds in fruit juice and peel oil of Jinchen sweet orange fruit (Citrus sinensis (L.) Osbeck) by GC-MS and GCO," Molecules, vol. 13, no. 6, pp. 1333-1344, 2008.

[28] C. S. Sell, "Linear and monocyclic terpenes," in A Fragrant Introduction to Terpenoid Chemistry, pp. 43-64, The Royal Society of Chemistry, Cambridge, UK, 2003.

[29] P. E. Shaw, "Aqueous essences," in Citrus Science and Technology: Volume 1 Nutrition, Anatomy, Chemical Composition and Bioregulation, S. Nagy, P. E. Shaw, and M. K. Veldhuis, Eds., pp. 463-475, AVI Publishing Company, Westport, CT, USA, 1977.

[30] A. F. Trasarti, A. J. Marchi, and C. R. Apesteguía, "Highly selective synthesis of menthols from citral in a one-step process," Journal of Catalysis, vol. 224, no. 2, pp. 484-488, 2004.

[31] A. Yani, G. Pauly, M. Faye, F. Salin, and M. Gleizes, “The effect of a long-term water stress on the metabolism and emission of terpenes of the foliage of Cupressus sempervirens," Plant, Cell \& Environment, vol. 16, no. 8, pp. 975-981, 1993.

[32] J. A. Attaway, A. P. Pieringer, and L. J. Barabas, "The origin of citrus flavor components-III. A study of the percentage variations in peel and leaf oil terpenes during one season," Phytochemistry, vol. 6, no. 1, pp. 25-32, 1967.

[33] R. M. Ikeda, W. L. Stanley, L. A. Rolle, and S. H. Vannier, "Monoterpene Hydrocarbon Composition of Citrus Oils," Journal of Food Science, vol. 27, no. 6, pp. 593-596, 1962.

[34] G. L. K. Hunter and W. B. Brogden, "Analysis of the Terpene and Sesquiterpene Hydrocarbons in Some Citrus Oils," Journal of Food Science, vol. 30, no. 3, pp. 383-387, 1965.

[35] R. L. Coleman and P. E. Shaw, "Analysis of Valencia Orange Essence and Aroma Oils," Journal of Agricultural and Food Chemistry, vol. 19, no. 3, pp. 520-523, 1971.

[36] M. K. Veldhuis, "Quantitative composition studies of watersoluble aromatics from orange peel," Journal of Agricultural and Food Chemistry, vol. 20, no. 3, pp. 685-687, 1972.

[37] P. E. Shaw and R. L. Coleman, "Quantitative composition of cold-pressed orange oils," Journal of Agricultural and Food Chemistry, vol. 22, no. 5, pp. 785-787, 1974. 
[38] S. B. Mitiku, M. Sawamura, T. Itoh, and H. Ukeda, "Volatile components of peel cold-pressed oils of two cultivars of sweet orange (Citrus sinensis (L.) Osbeck) from Ethiopia," Flavour and Fragrance Journal, vol. 15, no. 4, pp. 240-244, 2000.

[39] L. Mondello, A. Casilli, P. Q. Tranchida, R. Costa, P. Dugo, and G. Dugo, "Fast GC for the analysis of citrus oils," Journal of Chromatographic Science (JCS), vol. 42, no. 8, pp. 410-416, 2004.

[40] Y.-Y. Hsiao, W.-C. Tsai, C.-S. Kuoh et al., "Comparison of transcripts in Phalaenopsis bellina and Phalaenopsis equestris (Orchidaceae) flowers to deduce monoterpene biosynthesis pathway," BMC Plant Biology, vol. 6, article no. 14, 2006.

[41] S. Fatima, A. H. Abad Farooqi, and S. Sharma, "Physiological and metabolic responses of different genotypes of Cymbopogon martinii and C. winterianus to water stress," Plant Growth Regulation, vol. 37, no. 2, pp. 143-149, 2002.

[42] P. Cao, C. Liu, and K. Liu, "Aromatic constituents in fresh leaves of Lingtou Dancong tea induced by drought stress," Frontiers of Agriculture in China, vol. 1, no. 1, pp. 81-84, 2007. 

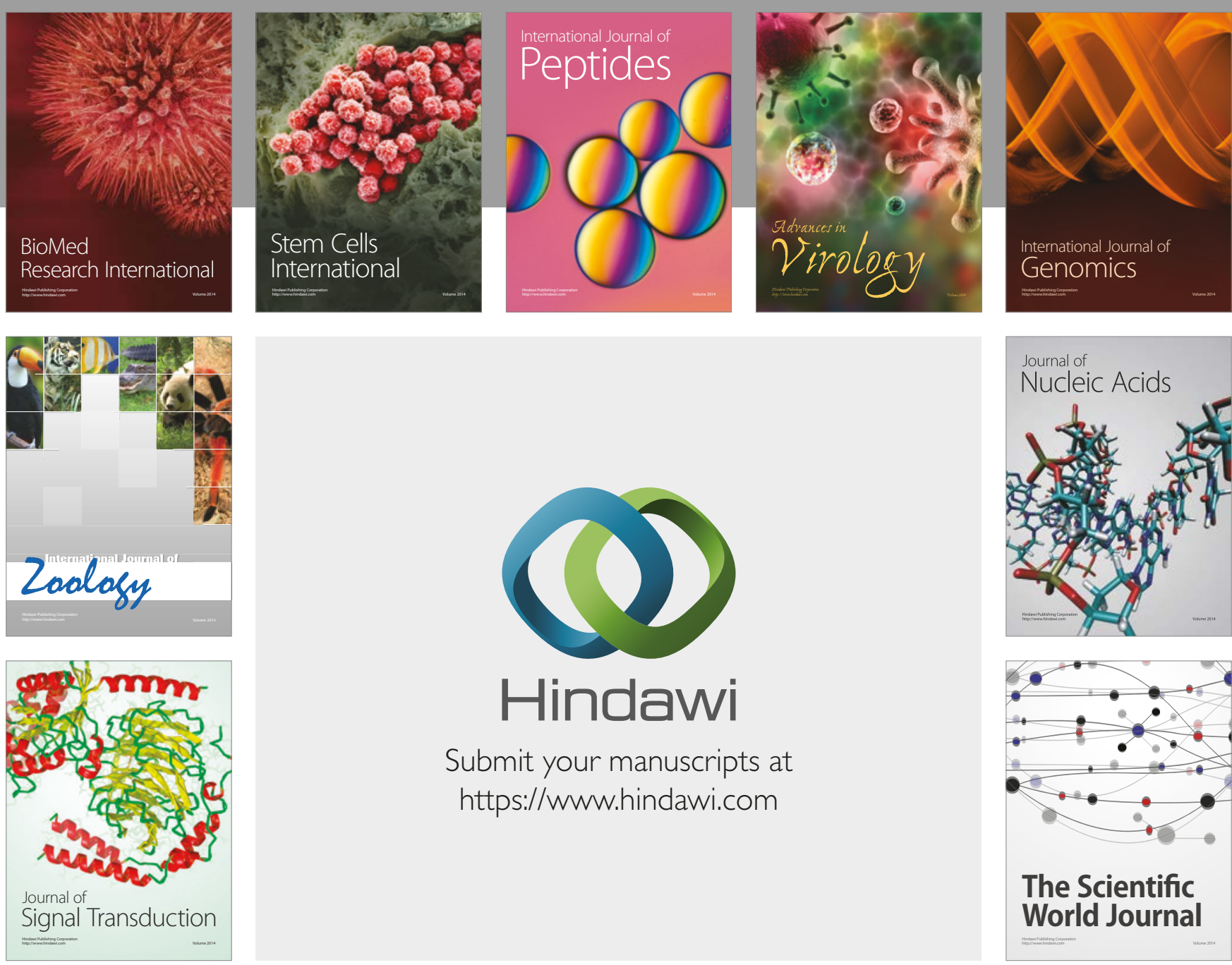

Submit your manuscripts at

https://www.hindawi.com
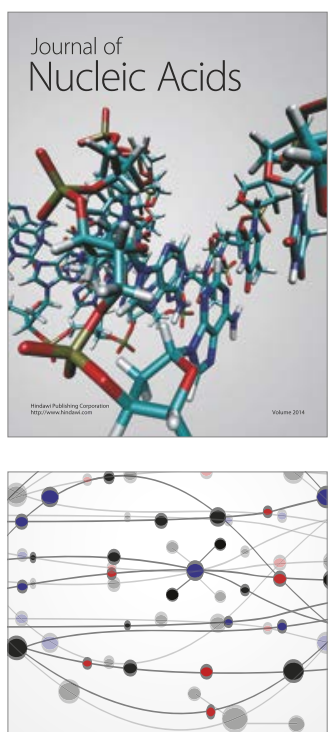

The Scientific World Journal

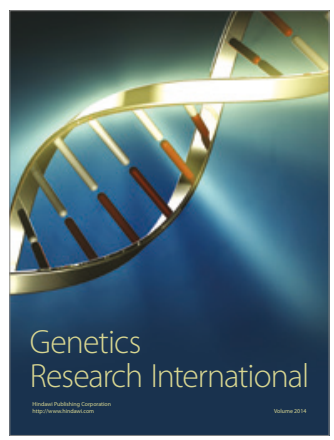

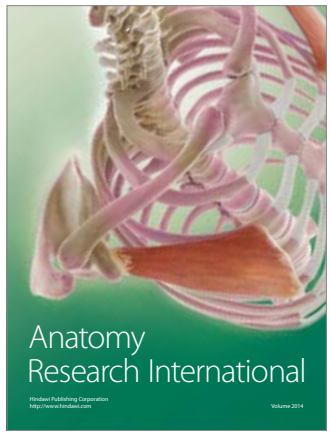

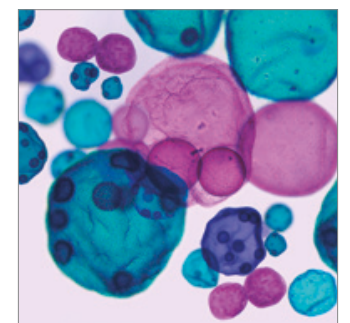

International Journal of Microbiology
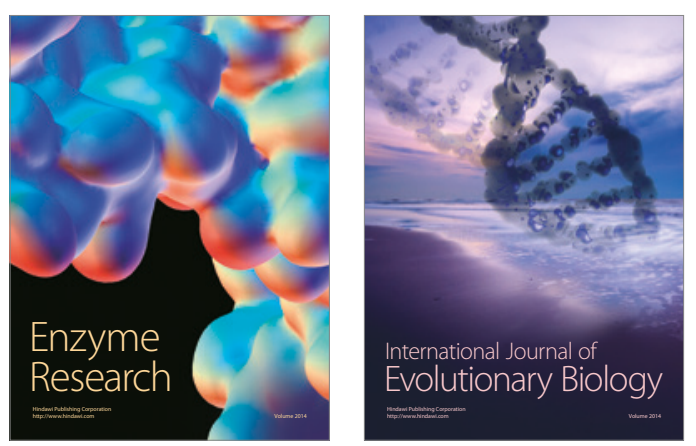
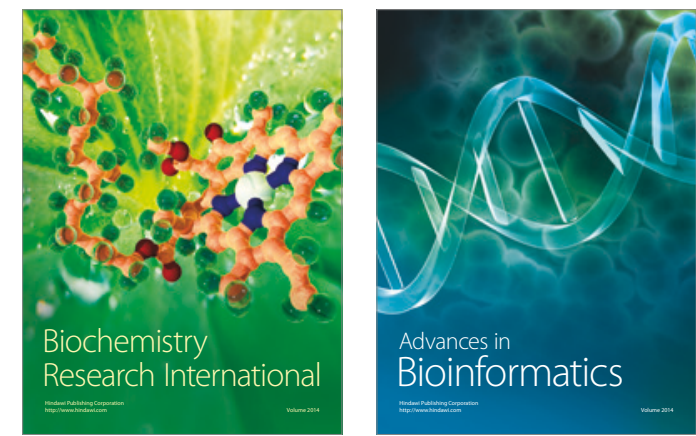

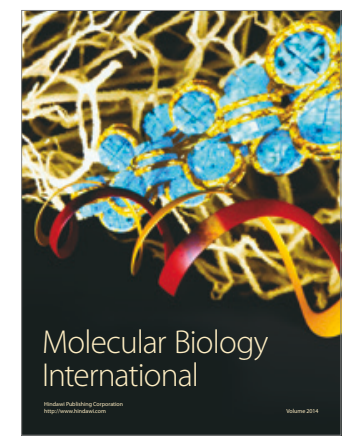

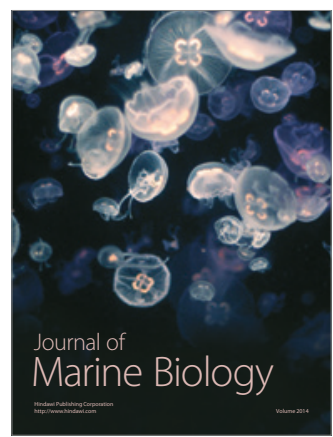

